\title{
Effects of sugarcane aphid herbivory on transcriptional responses of resistant and susceptible sorghum
}

\author{
Mahnaz Kiani* and Adrianna Szczepaniec
}

\begin{abstract}
Background: Sugarcane aphid (Melanaphis sacchari) outbreaks in sorghum that were first reported in 2013 are now the most significant threat to this crop in all major sorghum production areas in the U.S. The outcomes of interactions between sugarcane aphid and sorghum and thus the severity of the outbreaks depend on sorghum genotype and potentially also on the phenology of sorghum. Mechanisms underlying these interactions are not known, however. Thus, the goal of this research was to characterize transcriptional changes in a commercially available resistant and a susceptible genotype of sorghum at 2- and 6-wk post-emergence exposed to $M$. sacchari herbivory. The effects of sorghum age and genotype on the daily change in aphid densities were also evaluated in separate greenhouse experiments.

Results: A higher number of diffentially expressed genes (DEGs) was recovered from the 2-wk plants exposed to aphid herbivory compared to the 6-wk plants across genotypes. Further, gene ontology and pathway analysis indicated a suite of transcriptional changes in the resistant genotype that were weak or absent in the susceptible sorghum. Specifically, the aphid-resistant genotype exposed to M. sacchari up-regulated several genes involved in defense, which was particularly evident in the 2-wk plants that showed the most robust transcriptional responses. These transcriptional changes in the younger resistant sorghum were characterized by induction of hormone-signaling pathways, pathways coding for secondary metabolites, glutathion metabolism, and plant-pathogen interaction. Furthermore, the 2-wk resistant plants appeared to compensate for the effects of oxidative stress induced by sugarcane aphid herbivory with elevated expression of genes involved in detoxification. These transcriptional responses were reflected in the aphid population growth, which was significantly faster in the susceptible and older sorghum than in the resistant and younger plants.

Conclusion: This experiment provided the first insights into molecular mechanisms underlying lower population growth of $M$. sacchari on the resistant sorghum genotype. Further, it appears that the younger resistant sorghum was able to mount a robust defense response following aphid herbivory, which was much weaker in the older sorghum. Several pathways and specific genes provide specific clues into the mechanisms underlying host plant resistance to this invasive insect.
\end{abstract}

Keywords: Melanaphis sacchari, Sorghum bicolor, Plant-insect interaction, RNA-seq, Plant defenses

\footnotetext{
* Correspondence: Mahnaz.kianifariz@ag.tamu.edu

Department of Entomology, Texas A\&M AgriLife Research, 6500 Amarillo

Blvd. W, Amarillo, TX 79106, USA
}

(C) The Author(s). 2018 Open Access This article is distributed under the terms of the Creative Commons Attribution 4.0 International License (http://creativecommons.org/licenses/by/4.0/), which permits unrestricted use, distribution, and reproduction in any medium, provided you give appropriate credit to the original author(s) and the source, provide a link to the Creative Commons license, and indicate if changes were made. The Creative Commons Public Domain Dedication waiver (http://creativecommons.org/publicdomain/zero/1.0/) applies to the data made available in this article, unless otherwise stated. 


\section{Background}

Plants have evolved diverse strategies to defend, tolerate, or avoid insect herbivores $[1,2]$ that provide valuable resources for deploying in pest management [3, 4]. When plants detect the injury inflicted by herbivores, they finetune their responses through a flexible and finely balanced network that in turn activates specific defense responses [4, 5] with a large intraspecific variation in signaling cascades and production of metabolites [4]. The genetic diversity of herbivore-resistant traits is also a valuable resource for studying the mechanism of resistance and the ultimate deployment of them in crop breeding programs $[4,6]$. In fact, resistant cultivars and hybrids have been employed as an effective method for controlling economically damaging arthropods in many different crops, including sorghum [Sorghum bicolor (L.) Moench] [7-11], which is vulnerable to significant injury caused by diverse insect pests [12]. The employment of host-plant resistance in controlling greenbug, Schizaphis graminum Rodandi (Hemiptera: Aphididae), in sorghum is an example of an effective integrated pest management in this crop [13-16]. As a result of the selected resistance sources that were bred into commercial sorghum hybrids, the frequency of chemical control to suppress the pest was significantly reduced $[17,18]$.

Invasive pests pose unique challenges to crop protection, which was recently exemplified by an invasion of sugarcane aphid, Melanaphis sacchari Zehtner (Hemiptera: Aphididae), a new invasive pest threatening sorghum production in the U.S. $[19,20]$. While the species has been present in the U.S. in sugarcane for over a century, an invasion of a new haplotype [21] absent in the country prior to the outbreaks is thought to be responsible for the eruptive population dynamics of $M$. sacchari in sorghum, which were first reported in 2013 [22, 23]. Similar to many other invasive insects [24-26], the genetic diversity of $M$. sacchari is generally low [27, 28], and sugarcane aphids colonizing sorghum in the U.S. appear to be genetically identical [29].

Current tactics used to suppress sugarcane aphids rely primarily on insecticides, but the rapid aphid population growth and high dispersion can hinder the effectiveness of the insecticides [19]. Therefore, host plant resistance has been successfully deployed to alleviate the impact of sugarcane aphids on sorghum and has proven to be an effective suppression tactic in the field [30-32]. In fact, several sorghum varieties have high levels of resistance to sugarcane aphids [22, 33]. For example, Szczepaniec [32] reported that host plant resistance in the resistant genotype was the most effective factor in population dynamics of $M$. sacchari when compared to insecticide seed treatment or planting date. Specifically, densities of aphids were 2-2.5 times greater on the susceptible sorghum compared to the resistant hybrid. Further, it has been demonstrated in the field that populations of these aphids can reach exponential rate of increase within two weeks of colonizing post-bloom sorghum [32]. While suppressive effects of host plant resistance on aphid population growth were not surprising, the differences in aphid population growth between younger sorghum and sorghum close to reproductive stage have important consequences to ecology and management of the aphid. Sugarcane aphids colonize sorghum in vegetative stages in the southern U.S., where they can overwinter on non-crop vegetation [23], while wind-aided migration is responsible for aphid colonization of sorghum in reproductive stages in the northern states (e.g., High Plains) [32]. Mechanisms underlying sorghum resistance to sugarcane aphids across sorghum phenology are not well understood, however.

The molecular mechanisms underlying plant-aphid interactions, in general, have been studied extensively using molecular mapping and QTLs screening [34-36]. Over the last few years, however, as it became apparent that transcriptional re-programming is the backbone of many plant defense responses, the research has shifted toward transcriptomic analysis of herbivore-plant interactions. Aphid-resistant cultivars respond to aphid feeding by upregulation of diverse genes that contribute to aphid resistance [37-39]. These genes have been found to be involved in phytohormone signaling pathways, particularly salicylic acid (SA), jasmonic acid (JA), and ethylene (ET) [40-42]. Further, the production of plant secondary metabolites which are compounds that play a key role in defense and are often toxic to insects is another common induced response of plants exposed to insect herbivory [43, 44].

A comprehensive understanding of the molecular interactions between the susceptible and resistant sorghum and sugarcane aphid can provide insights into the mechanism of resistance and advance the potential to apply them to crop protection. Therefore, the goal of this research was to characterize transcriptional responses of a resistant and susceptible sorghum to herbivory by $M$. sacchari. Further, owing to the fact that these aphids can colonize sorghum at vegetative or at reproductive stages of sorghum development depending on the geographic location, we also explored if the interaction between sorghum resistance and sorghum age had an effect on gene expression and on population growth of the aphids. We hypothesized that expression of genes involved in defense pathways will be greater in the resistant and in younger sorghum than in the susceptible and in older sorghum and that the aphid population growth will reflect these differences.

\section{Results and discussion}

Mapping results and DEGs in resistant and susceptible sorghum exposed to aphid herbivory

Sequencing of 24 libraries generated 51.6 to 82.8 million reads from individual samples, and 43.9 to 68.8 million 
reads were uniquely mapped to sorghum reference genome sbicolor_454 v3.1.1. On average, $91 \%$ of the reads mapped to exonic regions (Additional file 1). A higher number of DEGs was recovered from the 2-wk plants exposed to aphid herbivory compared to the 6-wk plants across genotypes. The number of DEGs was also affected by genotype such that the resistant genotype had a higher number of DEGs in response to aphid herbivory at both 2- and 6-wk post-emergence than the susceptible genotype (Fig. 1). Of the 5955 DEGs in the 2-wk resistant genotype exposed to aphid herbivory, $54.9 \%$ were up-regulated and $45 \%$ were down-regulated. On the other hand, 62.6\% DEGs were up-regulated and 37.3\% were down-regulated in the 2-wk susceptible sorghum in response to the aphid (Additional files 2 and 3). Fewer responses were noted in the 6-wk sorghum. Specifically, the resistant genotype up-regulated 2376 genes while the susceptible genotype up-regulated only 985 genes when aphids were feeding on the plants (Additional files 4 and $5)$. The overlaps between different sets of DEGs representing changes in the 2- and 6-wk susceptible and resistant genotypes in response to aphid herbivory were further illustrated in Venn diagrams (Fig. 2). In the 2-wk sorghum, 2430 DEGs were shared between both genotypes in response to aphid herbivory, while 3525 and 986 DEGs were only expressed in the resistant and susceptible genotypes, respectively. This result indicates that the resistant 2-wk old sorghum responds to the aphid feeding by eliciting a higher number of unique responses than the susceptible genotype. On the other hand, 869 DEGs were shared between the two genotypes exposed to the aphids at 6 -wk post-emergence, and 3820 and 116 DEGs were uniquely expressed in resistant and susceptible genotype, respectively. The higher numbers of DEGs in the younger resistant genotype in response

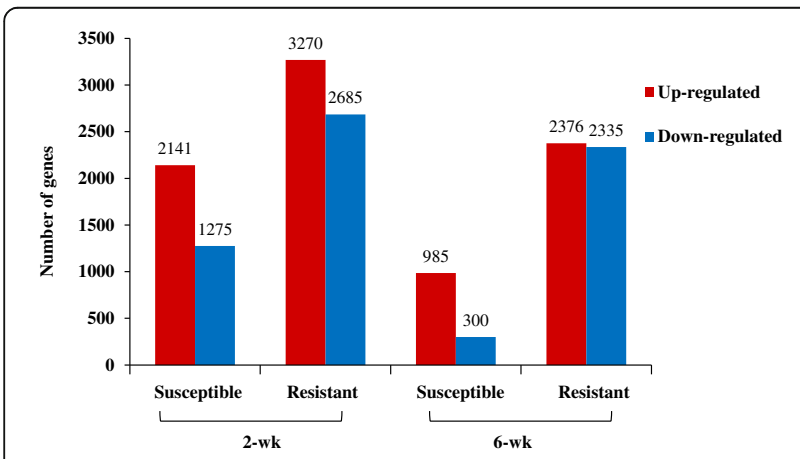

Fig. 1 Number of DEGs in sorghum genotypes in response to sugarcane aphid herbivory at 2- and 6-wk. Columns represent number of genes up-regulated or down-regulated following exposure to aphid herbivory compared to the equivalent genotype and age treatment free of the aphids. DEGs were defined as having a fold change $\geq 1.9$ or $\leq-1.9$ with a false discovery rate (FDR) adjusted $p$-value $<0.05$ to $M$. sacchari indicate that these plants were undergoing significant metabolic changes. This outcome was not surprising and has been reported previously. For example, Lee et al. [37] found higher number of DEGs in resistant soybean in response to soybean aphid, Aphis glycines Matsumura (Hemiptera: Aphididae) in comparison to an aphid-susceptible soybean line.

\section{Gene ontology (GO) analysis}

Aphid herbivory affected a higher number of significant GO terms in the 2-wk plants than in the 6-wk plants regardless of genotype (Fig. 3). In the resistant 2-wk genotype, up-regulated genes associated with metabolic process, biosynthetic process, macromolecule process, and oxidation reduction were included in the enriched biological process GO terms. "Oxidoreductase activity" was also the prominent enriched GO term in the molecular function category in the 2-wk resistant genotype (Fig. 3a). Similarly, we noted enrichment in polysaccharide biosynthesis, carbohydrate biosynthesis, metabolic process, and oxidation reduction GO terms in upregulated genes in the 2-wk susceptible genotype (Fig. $3 \mathrm{~b})$. The number of enriched GO terms in both up- and down-regulated genes was higher in the 6-wk resistant genotype (Fig. 3c) than in the 6-wk susceptible genotype (Fig. 3d). The majority of the down-regulated genes were enriched in several nucleotide binding GO terms, and it was noteworthy that "oxidoreductase activity" was the only GO term that was down-regulated in the 6-wk susceptible genotype (Fig. 3). On the other hand, genes involved in detoxification, which is one of the defenses linked to plant response to aphid herbivory [37, 45, 46] was up-regulated in both 2- and 6-wk resistant genotype and in the 2-wk susceptible genotype (Fig. 3a, b and c). The up-regulation of genes involved in oxidativereduction process has been reported in several plants in response to herbivory, such as in barly in response to Diuraphis noxia Kurdjumov (Hemiptera: Aphididae) [47], in switchgrass exposed to greenbug [48], in soybean at both compatible and incompatible interactions with soybean aphid [37, 49], and in cotton in response to Bemisia tabaci Gennadius (Hemiptera: Aleyrodidae) [46]. Our outcomes corroborate these studies and suggest that oxidative responses that are elicited in the resistant genotype are may be the key components of sorghum resistance to sugarcane aphids.

\section{KEGG pathway analysis overview}

Pathway analysis revealed significant effects of the genotype on a number of enriched pathways (Fig. 4). Specifically, 3270 genes that mapped to 24 pathways were up-regulated in the 2-wk resistant genotype in response to aphid herbivory, while 1275 up-regulated genes from 10 pathways were elicited in the 2-wk 
a

Susceptible A+ vs Resistant A+ Resistant A+ vs Resistant A-

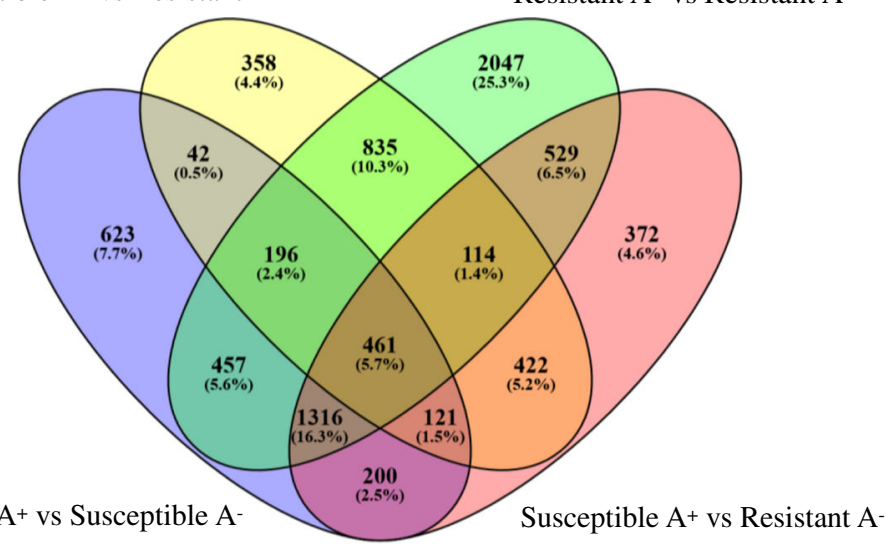

Susceptible A+ vs Susceptible A-

6-wk

\section{b}

Resistant $\mathrm{A}^{+}$vs Resistant A-

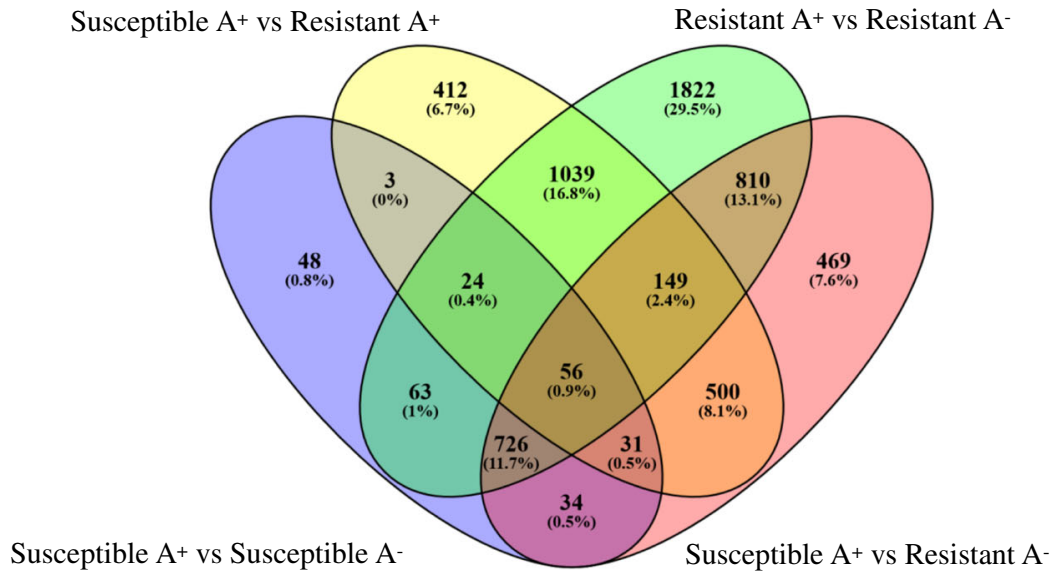

Fig. 2 Venn diagram of DEGs in susceptible and resistant sorghum genotypes exposed to sugarcane aphid herbivory. DEGs were compared in 2-wk (a) and 6-wk (b) sorghum plants in response to aphid herbivory $\left(\mathrm{A}^{+}\right)$and in aphid-free $\left(\mathrm{A}^{-}\right)$plants. All overlapped and unique DEGs from different comparisons are shown

susceptible genotype (Fig. 4a, b). Fewer pathways were enriched in the 6-wk old sorghum.

In general, we found that a significantly higher number of pathways were up regulated rather than downregulated in the 2-wk old plants regardless of the genotype (Fig. 4a, b). It is noteworthy that in our study plant hormone signal transduction and glutathione metabolism pathways, both shown previously to be highly relevant to plant defense [4,50-52], were only enriched in the 2-wk resistant genotype along with a plant-pathogen interaction pathway (Fig. 4a). Induction of specific genes within these pathways suggests that their higher expression may be driving resistance to the aphids in this genotype, which appears the strongest in younger plants. In the susceptible 2-wk plants, biosynthesis of secondary metabolites, phenylpropanoid biosynthesis, and biosynthesis of flavonoids associated with plant defense and stress responses were up-regulated in response to aphid herbivory (Fig. 4b).

Aphids induced expression of genes in defense pathways in the 6-wk resistant genotype as well. These pathways included biosynthesis of secondary metabolites, phenylpropanoid biosynthesis, plant-pathogen interaction, and linoleic acid metabolism. However, the magnitude of these inductions was lower than in the younger sorghum (Fig. 4c). Biosynthesis of secondary metabolites and phenylpropanoid pathway were also enriched in the 6-wk susceptible sorghum (Fig. 4d), but the number of up-regulated genes was lower in these pathways compared with the 2-wk plants 
a

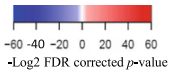

$-60-40-20 \quad 20 \quad 40$
$-L o g 2$ FDR corrected $p$-value b

2-wk resistant $-60-40-20 \quad 0 \quad 20 \quad 40 \quad 60$
- - -22 FDR corrected $p$-value

2-wk susceptible

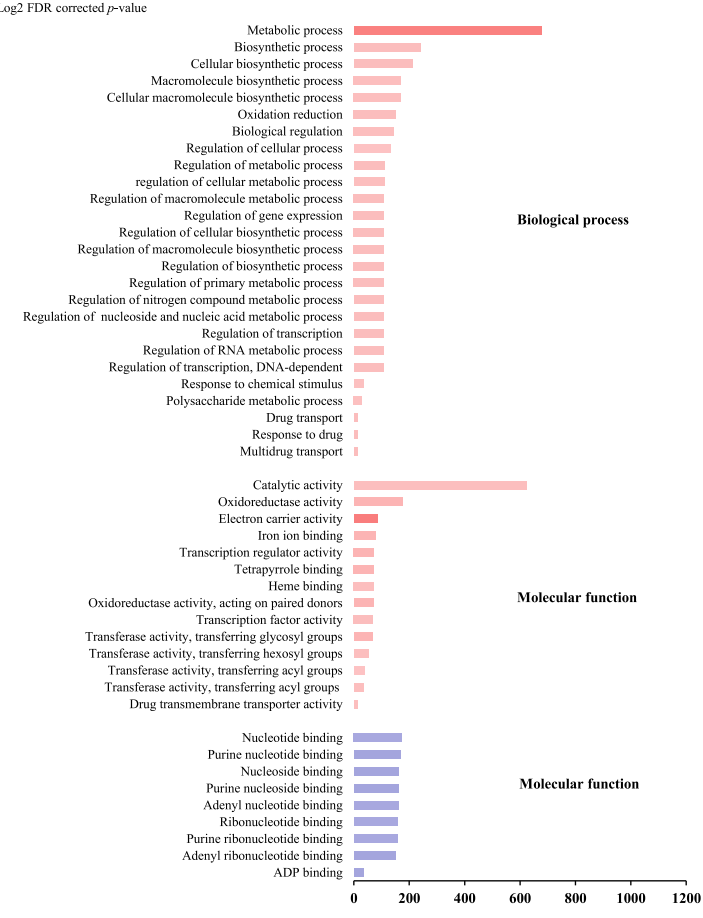

d

\section{C}

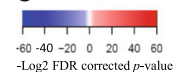

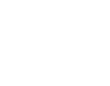

Cellular biosynthetic process

Macromolecule biosynthetic process
Cellular macromolecule biosynthetic process

Gene expression

Oxidation reduction

Translation

Oxidoreductase activity

Structural molecule activity

Structural constituent of ribosome

Cytoplasm

Cytoplasmic part

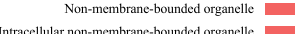

Ribonucleoprotein complex

Ribosome

Nucleotide binding

Purine nucleotide binding

Adenyl nucleotide binding

Nucleoside binding

Rive

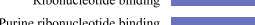

Purine ribonuclcotide binding

Transferase activity, transferring phosphorus-containing groups

ADP binding
RNA methyltransferase activity

$\begin{array}{llllll}200 & 400 & 600 & 800 & 1000 & 1200\end{array}$

Molecular function

$-\log 2$ FDR corrected $p$-value

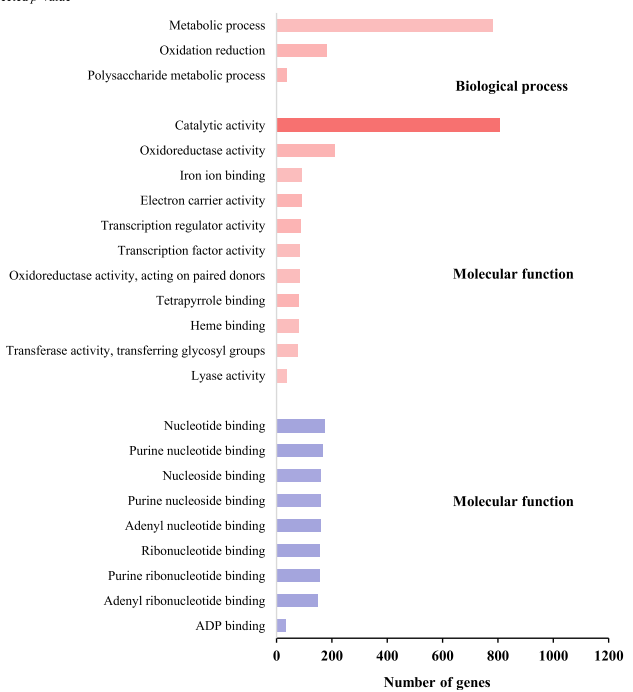

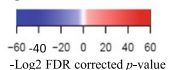

6-wk resistant

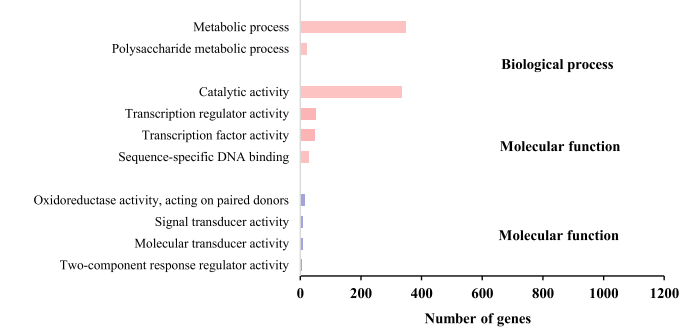

Fig. 3 Enriched Gene Ontology (GO) terms in the two sorghum genotypes in response to aphid herbivory. GO terms were compared among the 2-wk old resistant sorghum a, 2-wk old susceptible sorghum b, 6-wk old resistant sorghum $\mathbf{c}$, and the 6-wk old susceptible sorghum (d). GO terms (FDR corrected $p$-value $<0.05$ ) with significant numbers of up-regulated or down-regulated genes were identified by contrasting gene expression in response to aphid herbivory and control (aphid-free plants). DEGs were then grouped into and biological process, molecular function, and cellular component categories. Color of the bars refers to the $-\log ^{2}$ corrected $p$-value of the respective GO term. Red colored bars indicate enriched GO terms in up-regulated genes, and blue colored bars indicate enriched pathways in down-regulated genes. The darker the red color the higher statistical significance 
a

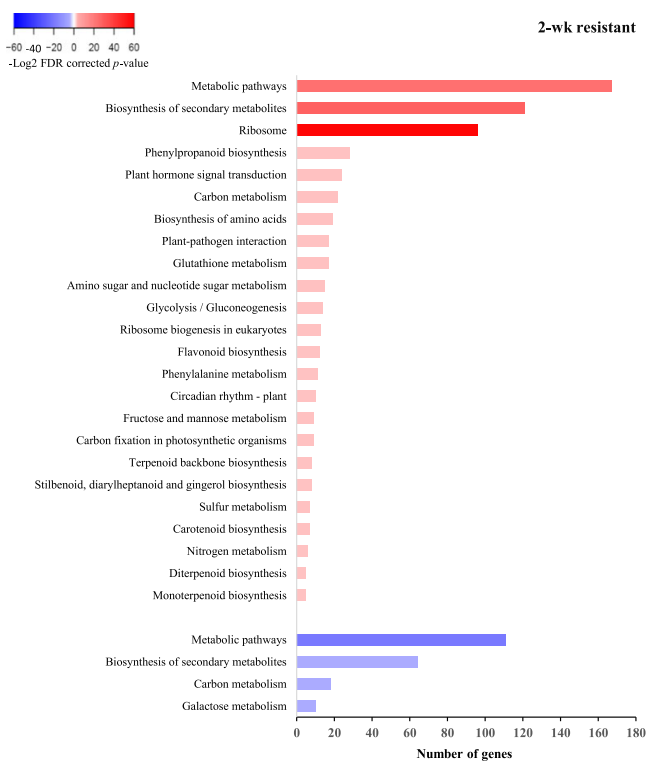

C

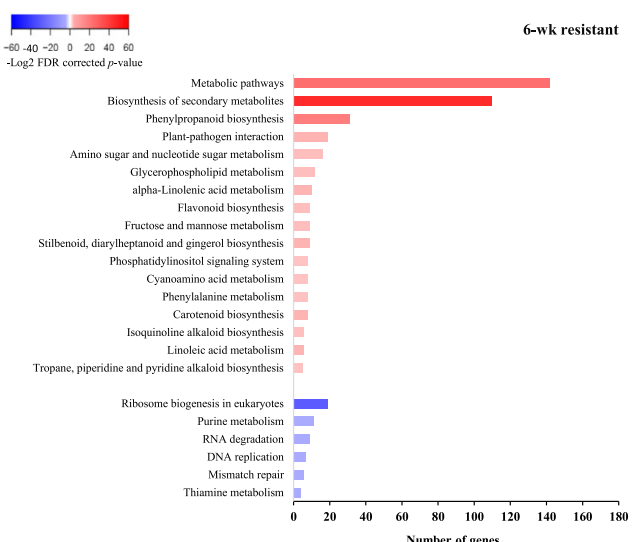

b

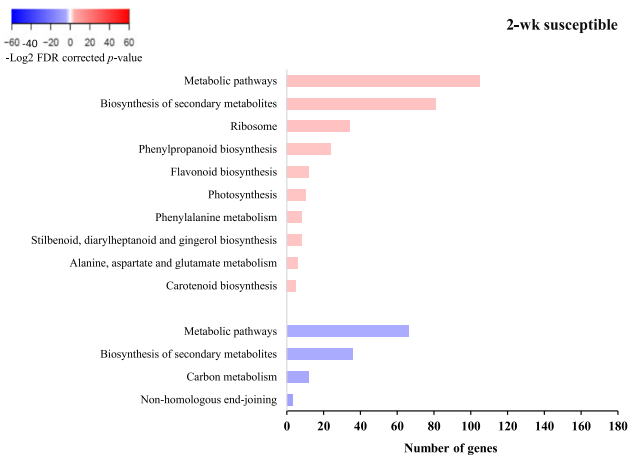

d

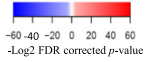

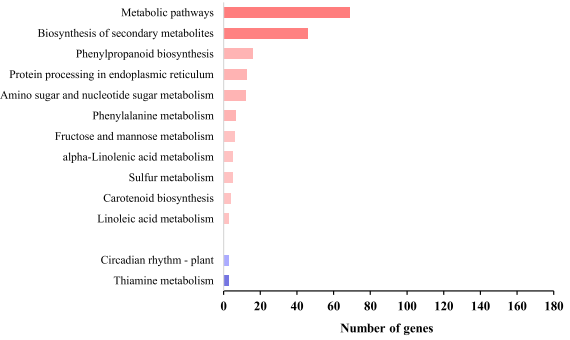

Biosynthesis of sccondary metabolites

biosynhesis

Fig. 4 Pathways enriched in DEGs from two sorghum genotypes in response to sugarcane aphid herbivory. Pathways were compared among the 2-wk old resistant sorghum a, 2-wk old susceptible sorghum b, 6-wk old resistant sorghum c, and the 6-wk old susceptible sorghum (d) Pathways (FDR corrected $p$-value $<0.05$ ) with significant numbers of up-regulated or down-regulated genes were identified by comparing gene expression in response to aphid herbivory and control (aphid-free plants). Color of the bars refers to the $-\log ^{2}$ corrected $p$-value of the respective pathway. Red colored bars indicate enriched pathways in up-regulated genes, and blue colored bars indicate enriched pathways in downregulated genes. The darker the red color the higher statistical significance. Length of the bar represents the number of genes within the respective $\mathrm{GO}$ term

regardless of genotype. Tu et al. [53] reported that synthesis of linoleic acid in response to thrips, Odontothrips loti Haliday (Thysanoptera: Thripidae) increased only in the resistant alfalfa cultivar and not in the susceptible cultivar. Moreover, Ponzio et al. [54] also reported that aphid infestation in Brassica nigra caused the increasing of the linoleic acid. These secondary metabolites have been previously shown to be induced by herbivory in general $[43,55]$. For example, Dubey et al. [56] reported the induction of transcripts related to secondary metabolite processes including phenylpropanoid and flavonoid biosynthesis in cotton exposed to A. gossypii. Further, Liang et al.
[38] reported induction of genes involved in signal transduction, flavenoid metabolism, and plant-pathogen interactions that were likely invovled in resistance of cucumber to A. gossypii.

\section{Specific genes and pathways relevant to sorghum resistance to $M$. sacchari}

Based on the GO enrichment analysis and KEGG pathway enrichment analysis, we identified multiple defenserelated genes that were differentially expressed in response to aphid herbivory. These aphid-responsive genes were grouped according to their function and discussed 
further. Specifically, we focused on signaling related genes, which act as mediators of herbivory-induced changes that occur during the early phases of the attack $[4,46,57,58]$ and phytohormone signaling pathways. We also elaborate on pathways and genes involved in secondary metabolism and stress response, and transcription factors (TFs), which are essential for the regulation of gene expression [59].

\section{Signaling-related genes: Calcium sensors, ROS, and MAPKs} A number of genes from the $\mathrm{Ca}^{2+}$ sensors group were up-regulated in response to aphid herbivory regardless of genotype or sorghum age. These genes encode calmodulinlike (CMLs) and calmodulin (CAM) proteins that are important in herbivore defense pathways in plants $[57,60]$. We noted several genes from this family to be affected by exposure to the aphids. For example, gene Sobic.001G393 500 from the CAM gene family showed higher expression in response to aphid herbivory regardless of genotype and age, while another gene from this family, Sobic.008G159100 was up-regulated in the 6-wk sorghum (Additional files 2, 3,4 and 5). Further, the majority of mitogen-activated protein kinases (MAPKs) genes including LPR receptor-like, and serine/threonine-protein kinase were up-regulated in response to aphid herbivory in the resistant genotype regardless of age. The activation of MAPKs, in turn, can phosphorylate transcriptional regulators and ultimately affect gene transcription [61]. The serine/threonine-protein kinase OXI1 gene (Sobic.006G128200), involved in signaling pathway by producing reactive oxygen species (ROS), was up-regulated in response to aphid across sorghum genotypes and age. The OXI1 gene in Arabidopsis has been reported to be required for resistance to downy mildew infection [62]. Moreover, genes from the protein phosphatase $2 \mathrm{C}$ family (PP2C) involved in phosphorylation were also up-regulated in response to the aphid herbivory. Plant PP2Cs have been reported to be relevant to plant stress signaling [63, 64].

Signaling-related genes: Plant hormone signal transduction In hormone signal transduction pathways, the majority of DEGs (25 genes) were up-regulated in the 2-wk resistant genotype in response to aphid herbivory (Fig. 5). These genes belong to the SA, JA, abscisic acid (ABA), auxin, cytokinins (CKs), and ET signal transduction pathways. Among these phytohormones, salicylic acid plays an important role in mediating induced plant responses to pathogens in particular $[40,65,66]$, but has been implicated in herbivore responses as well $[67,68]$. In this pathway, Sobic.001G143000 gene [NONEXPRESSOR OF PATHOGENESIS-RELATED GENE 1 (NPR1)], had a 10.6- and 2.4-fold increase in expression in response to aphid herbivory in both 2- and 6-wk resistant genotype, respectively (Additional files 2 and 4). In the susceptible genotype, three NPR1 genes were upregulated only in the 2-wk plants exposed to the aphids (Additional file 3). The NPR1 is a SA receptor protein and the transcriptional regulation of NPR1 is a key factor in regulation of defense signaling responses downstream of SA [69, 70].

Several DEGs in the JA signaling pathway that regulates direct and indirect plant responses against herbivores [71-73] were also induced in our experiment. These DEGs included genes from the jasmonate ZIM-domain (JAZ) family, which function as repressors of JA signal output and high levels of JAZ proteins control the JA responses by repressing their transcription factors [73, 74]. These genes had more than 2-fold change in response to aphid herbivory in the 2- and 6-wk resistant and susceptible genotype (Fig. 5). They are located up-stream of $M Y C 2$ transcription factor and act as the negative regulator of $M Y C 2$ function. The $M Y C 2$ transcription factor, on the other hand, increases JA-mediated resistance to insect pests [75]. These interactions are examples of negative crosstalk between JA and SA [76, 77], and the outcomes of our experiments indicate an antagonistic interaction between these hormones in sorghum exposed to aphid herbivory. We noted the greatest expression of NPR1 genes along with up-regulation of $J A Z$ genes that act as negative regulator of the JA-signaling pathway in both 2- and 6-wk resistant and in the 2-wk susceptible genotype. On the other hand, JAZ genes were upregulated while NPR1 gene expression was unaffected in the 6-wk susceptible genotype, which had the weakest overall transcriptional responses to aphid herbivory. As has been reported previously [40,78], interactions between JA and SA are complex and can be host- [79] and herbivore-specific [80]. Moreover, it has been suggested that insects can manipulate plant defenses by modulating the JA/SA crosstalk [81-83]. Therefore, we speculate that up-regulation of $J A Z$ genes may be mediated by sugarcane aphids in order to suppress host defense strategies. This was previously demonstrated by Moran, Thompson [84] who reported that green peach aphid (Myzus persicae Sulzer, Hemiptera: Aphididae) and greenbug aphid feeding on Arabidopsis and sorghum respectively, up-regulated SA-dependent pathway and reduced activation of JA-dependent defenses in host plants.

Abscisic acid is a plant hormone involved primarily in the perception of abiotic stresses [85-87], which can be elicited by aphid herbivory $[88,89]$. Four genes in the ABA signaling cascade were up-regulated in the resistant 2-wk sorghum including Sobic.006G279100, Sobic.001 G350700 genes encoding SNF1-related protein kinase 2 (SnRK2, a positive regulator of ABA), and Sobic.003G19 8200 , Sobic.001G424400 genes coding for type 2C protein phosphates (PP2C, a negative regulator of $\mathrm{ABA}$ ) (Additional file 2). Five genes in this pathway were also 


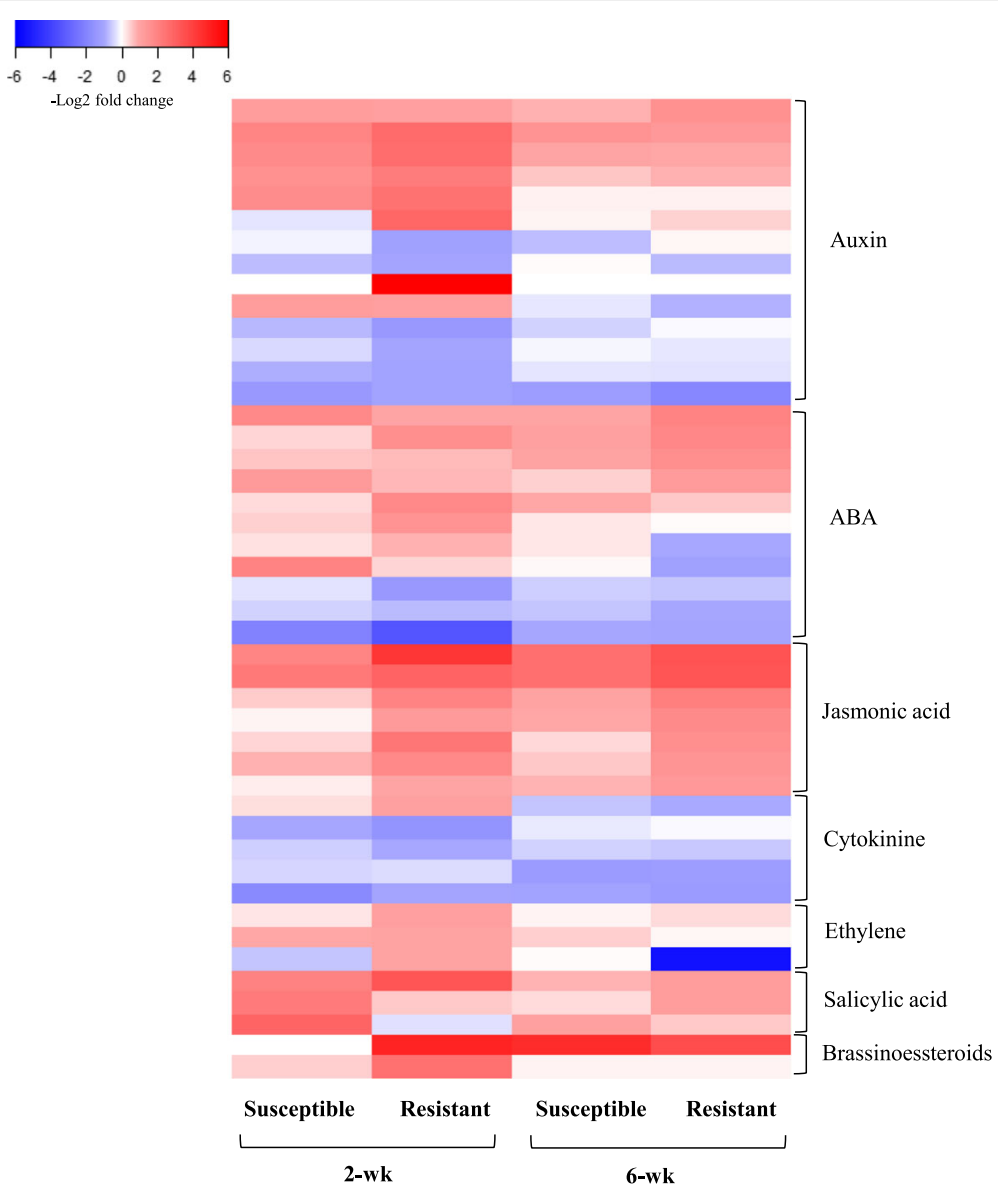

Fig. 5 Heat map of DEGs involved in hormone transduction pathways in response to aphid herbivory. Heat map shows DEGs across two resistant and susceptible sorghum genotypes at 2- and 6-wk post-emergence. The color key represents log2-transformed fold changes and red indicate increased expression in response to aphid, while blue represents a decrease in expression

up-regulated in the resistant 6-wk sorhgum, including bZIP23 transcription factor (Sobic.004G309600), which showed 3.2-fold induction in response to aphid herbivory (Additional file 4). Zong et al. [90] reported that OsbZIP23 acts as a central regulator in ABA signaling, biosynthesis, and drought resistance in rice. Therefore, the effects of aphid feeding on inducing of ABA signaling are likely related to induced water stress [91, 92].

Genes involved in auxin signaling pathway were also differentially expressed in both resistant and susceptible genotypes (Fig. 5). Auxin is involved in regulation of plant growth and development, and activation of auxin signaling is usually linked to increased disease susceptibility [93, 94]. The majority of these genes were up-regulated in 2-wk sorghum regardless of genotype (Fig. 5). However, there were key differences between the resistant and susceptible 2-wk old plants. Specifically, two members of $A U X / I A A$ gene family i.e. Sobic.009 G069700 and Sobic.002G055900 that act as a transcriptional repressor were up-regulated in the 2-wk resistant genotype in response to aphid herbivory, but only Sobic.
$002 G 055900$ gene was up-regulated in the susceptible 2 -wk genotype (Additional files 2 and 3). While these trends in expression are potentially important, it is not clear if these subtle transcriptional responses can explain why sugarcane aphid performance differs among genotypes.

The SA-regulated auxin homeostasis, in general, has interesting implications for the trade-off between growth and defense $[95,96]$ such that higher SA levels reduce the pool of active indole-3-acetic acid [97] and subsequently defense is prioritized over growth. On the other hand, in absence of pathogens, auxinmediated suppression of SA responses can have positive consequences for plant growth [98]. In our experiment, Sobic.002G361500 encoding GH3-8, an auxin-responsive gene involved in processes that halt accumulation of free IAA, showed a 6.6- and 3.9-fold increases in expression in response to aphid herbivory in 2-wk resistant and susceptible genotype, respectively (Additional files 2 and 3). This suggests that up-regulation of these genes may have triggered a 
change in allocation of resources from growth to defense and conferred greater resistance to the aphids in the younger plants. It has been also reported that auxin-regulated genes such as $A U X / I A A$ and $G H$, are involved in an inhibitory feedback loop that maintains cellular auxin homeostasis that is required for adjusting auxin concentration for the optimal plant growth and development [99-101]. Induction of these genes in the 2-wk sorghum regardless of genotype but not in the 6-wk old sorghum suggests that the younger plants may be diverting their resources from primary to secondary metabolism thus increasing their resistance to the herbivore. However, more research is needed to unequivocally link these transcriptional responses to decreased aphid performance in the younger and resistant sorghum.

Cytokinins are plant hormones that act as key regulators of plant growth-defense trade-off and are also involved in plant-biotic interactions $[98,102]$. We found a number of significantly induced genes in cytokinine signaling pathway, several of which were induced in the absence of aphids and suppressed when aphids were feeding on the plants. Specifically, in the 2-wk aphid-free resistant sorghum, three positive cytokinine regulator genes (Sobic.009G202900, Sobic.O 03G292600, and Sobic.004G330900) were up-regulated, indicating that plants were regulating their growth processes actively (Additional file 2). On the other hand, Sobic.006G 090300 gene, a two-component response regulator ORR1 that acts as a negative regulator of cytokinine [98] was up-regulated in 2-wk resistant genotype exposed to aphid herbivory, suggesting that the younger resistant plants were suppressing their growth-related processes (Additional file 2 ). This outcome provides another example of the younger resistant sorghum switching from growth to defense in response to the aphids and highlights the lack of parallel responses in the susceptible sorghum. These results indicate a potential trade-off between growth and defense, which are both metabolically costly processes that usually cannot be carried out concurrently at high levels [96].

Ethylene is one of induced defense related phytohormones that is produced in response to multiple stresses $[103,104]$. Ethylene expression decreases with plant age, with a marked decline at the onset of reproduction associated with a significant reduction in the ability of plants to induce defenses [105]. This was consistent with our results - we found ethylene gene expression only in the younger plants. In ethylene signaling pathway, two genes i.e. Sobic.007G210700 and Sobic.009G050400, involved in the ethylene pathway were both up-regulated in the resistant 2-wk genotype in response to aphid and only Sobic.007G210700 was up-regulated in the susceptible 2 -wk genotype (Additional files 2 and 3). The release of ethylene in response to aphid herbivory has been reported in other host plant species [2, 106, 107].

\section{Secondary metabolites related to oxidative stress response genes}

A number of DEGs affected by aphid herbivory in our study are involved in metabolite synthesis through phenylpropanoid and flavonoid biosynthesis pathways. In addition, several other genes that were induced regulate plant responses to oxidative stress caused by herbivory. A number of genes in phenylpropanoid biosynthesis pathway showed differential expression in both susceptible and resistant genotypes exposed to the aphids (Fig. 6). Specifically, two genes Sobic.004G220400 and Sobic.004220700, both encoding phenylalanine ammonia-lyase (PAL) showed more than 2 -fold increase in response to aphid herbivory in both the 2- and 6-wk resistant and susceptible genotypes (Additional files $2,3,4,5)$. Phenylalanine ammonia-lyase catalyzes the first step of the phenylpropanoid pathway, which is a key reaction in the control of lignin, flavonoid and salicylic acid biosynthesis [108]. Lv et al. [108] reported that expression of $P A L$ was significantly increased in cotton and corn seedlings damaged by mechanical wounding or by cotton aphid and corn borer, Ostrinia furnacalis Guenée (Lepidoptera: Crambidae) herbivory. Further, Chaman et al. [109] reported a positive relationship between SA concentration, $P A L$ activity, and resistance of barley to aphid infestations. Therefore, induction of these genes across sorghum genotypes and age in our experiment indicates that they play a key role in sorghum response to aphid herbivory regardless of sorghum age or genotype.

Genes that were involved in response to oxidative stress belong to glutathione S-transferase, L-ascorbate peroxidase, peroxidase, and cytochrome $P 450$ gene family. The up-regulation of a number of genes involved in glutathione metabolism pathway was mostly found in the resistant 2-wk sorghum in response to aphid herbivory (Additional file 2). It has been proposed that the activation of glutathione metabolism is a natural cell response to stress that can be induced by aphids in general $[56,110]$, and the increase in expression of enzymes involved in glutathione synthesis is correlated with resistance to various biotic challenges [111] and in the detoxification of ROS [112]. Further, among the DEGs involved in phenylpropanoid pathway in our experiment, a higher number of genes encoding peroxidase showed differential expression in response to aphid herbivory in younger plants in comparison with older ones regardless of genotype. Peroxidases not only code for ROS-detoxifying enzymes but are also involved in oxidative signal transduction, regulating the redox and $\mathrm{Ca}^{2+}$ homeostasis as well as the expression of defense genes [113-115]. Higher expression of peroxidases has been reported previously in barley exposed to Diuraphis noxia (Hemiptera: Aphididae) [47], and in tomato fed upon by Macrosyphum euphorbiae (Hemiptera: Aphididae) [58]. Likewise, the cytochrome P450 superfamily genes were another abundant gene family that was induced in response to oxidative 

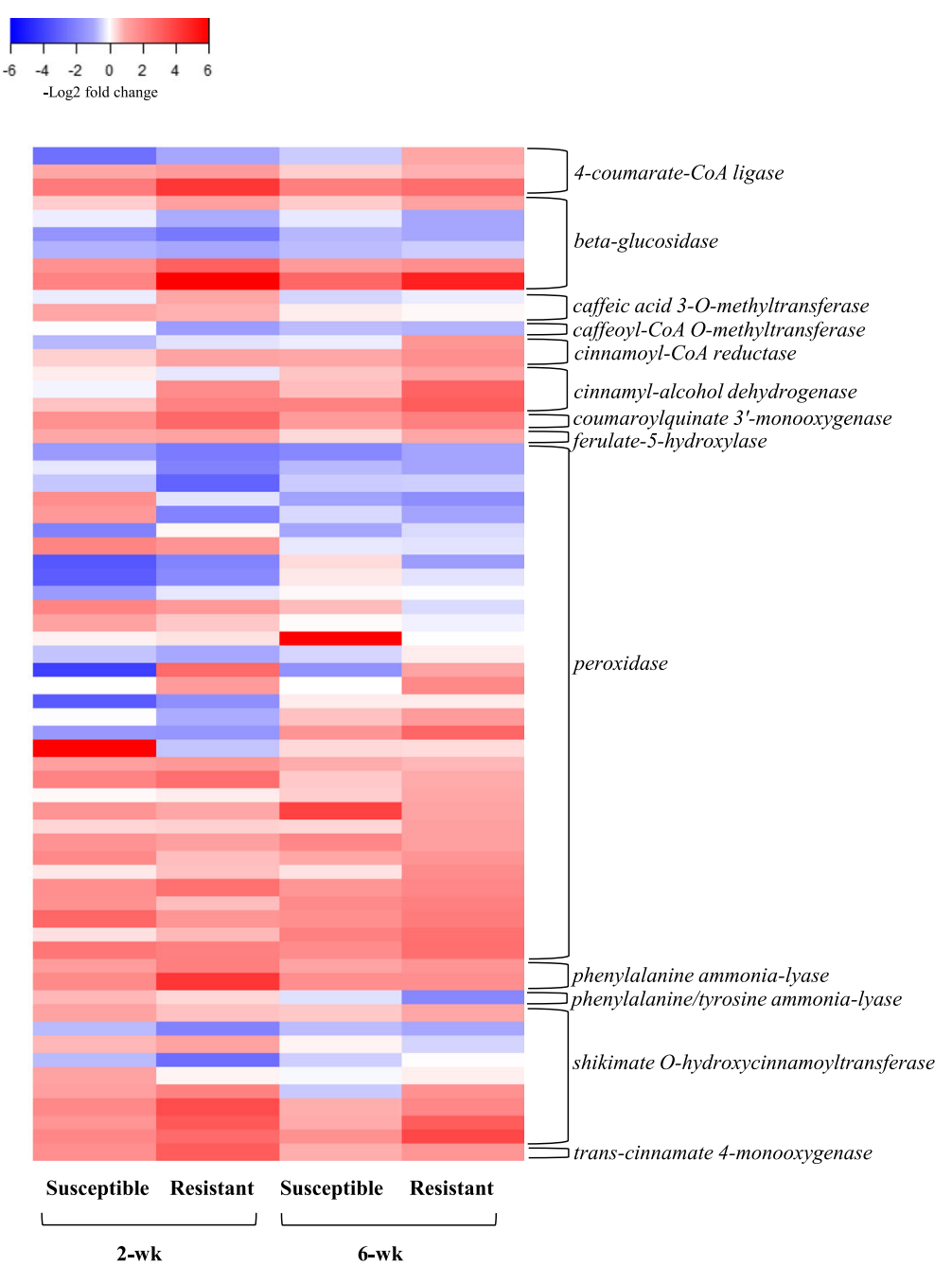

Fig. 6 Heat map of DEGs involved in phenylpropanoid biosynthesis pathway. Heat map presents DEGs across two resistant and susceptible sorghum genotypes at 2- and 6-wk post emergence. The color key represents log2-transformed fold changes and red indicate increased expression in response to aphid, while blue represents a decrease in expression

stress imposed by the aphids in our study. This gene family plays a crucial role in plant defense via multiple biosynthetic and detoxification pathways [116]. Prochaska et al. [39], for example, reported that genes from cytochrome P450 family were up-regulated in the resistant genotype of soybean in response to aphid herbivory. Notably, we found these genes to be induced the strongest in the 2-wk resistant sorghum exposed to sugarcane aphids (Additional file 2), which may explain the superior host plant resistance observed in this genotype shortly after emergence.

\section{DEGs encoding transcription factors}

Our results indicated differential expression of 71 genes encoding transcription factors (TFs) including WRKY, $M Y B, b H L H, N A C$, and AP2/ERF. The WRKY family of TFs is unique to plants and is involved in regulation of defense responses to pathogens and insects $[117,118]$.
The involvement of selected WRKY family in response to biotic stresses has been reported in Arabidopsis [119, 120], and we also tracked the expression of the orthologs of these genes in sorghum. Specifically, we found the highest number of differentially expressed TFs (52) in the resistant genotype and in the younger plants, and 18 of these TFs belonged to the WRKY family. In the 6-wk resistant genotype, a total of $42 \mathrm{TFs}$ were up regulated in response to aphid herbivory, and 13 of these were WRKY TFs. A comparable number of WRKY genes were upregulated in response to aphid herbivory in the 2- and 6-wk susceptible plants (Fig. 7). It is noteworthy that four WRKY transcription factors were found to be expressed exclusively in the 2-wk resistant genotype exposed to the aphids, including WRKY1 (Sobic.001G095500), WRKY19 (Sobic.009G238200), WRKY28 (Sobic.003G199400) and WRKY72 (Sobic.005G117400) (Additional file 2). The 

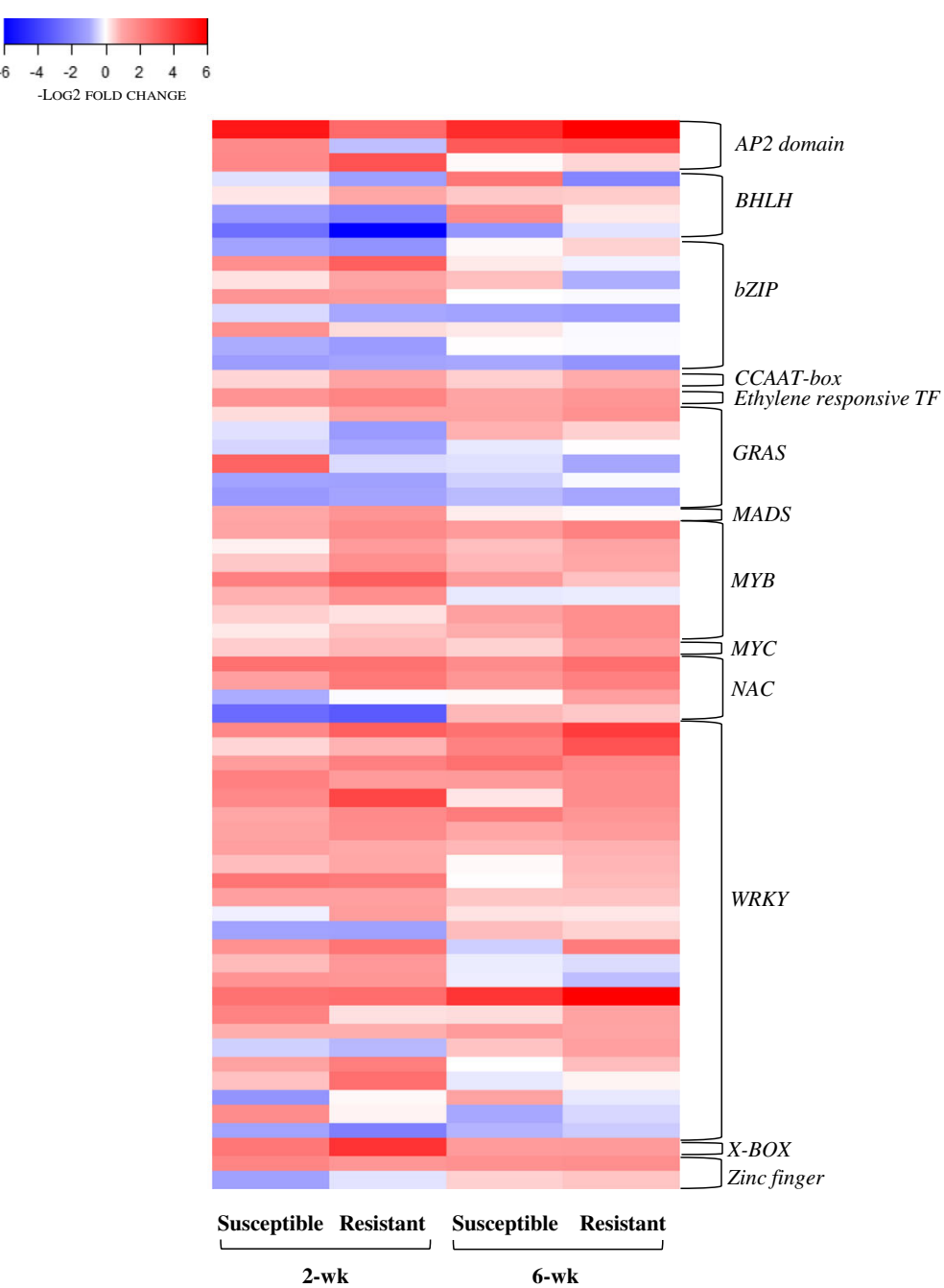

Fig. 7 Heat map of differentially expressed transcription factors. Heat map shows DEGs across two resistant and susceptible sorghum genotypes at 2- and 6-wk post-emergence. The color key represents log2-transformed fold changes and red indicate increased expression in response to aphid, while blue represents a decrease in expression

involvement of the homologs of these genes in hormone signaling pathways and response to abiotic stresses has been reported in Arabidopsis [42, 78, 119, 121]. For example, the homolog of WRKY19 in Arabidopsis, i.e., AT4G11070 has been shown to be a key regulator of cross-talk between SA and JA signaling pathways [122]. Our outcomes corroborate these reports - the sorghum orthologs of AtWRKY70 i.e. Sobic.003G337900, and Sobic.008G060300 were only expressed in response to aphid herbivory in 2-wk plants regardless of genotype, with higher expression in the resistant genotype. Similarly, the AtWRKY4O ortholog in sorghum, i.e. Sobic.004G065900, was up-regulated in response to aphid herbivory regardless of genotype and age. The up-regulation of AtWRKY40 has been reported in Arabidopsis in response to cabbage aphid, Brevicoryne brassica (Hemiptera: Aphididae) [120]. Three TFs with AP2 domain i.e., Sobic.002G415600, Sobic.003G380900, and Sobic.004G310600, prominent TF regulators of host defense [123, 124], were up-regulated in response to aphid herbivory across genotypes and sorghum age. Other types of TFs identified among the DEGs were $b Z I P, b H L H$, $M Y B, N A C$, zinc finger, several of which have been reported to be important for plant adaptive response to biotic stress $[125,126]$.

\section{Real-time quantitative RT-PCR (RT-qPCR) of selected DEGs} All genes selected for validation of RNA-seq data showed a similar expression trend (up-regulation or down-regulation) in the RT-qPCR analysis. High correlations (all above $R^{2}>0.70$ ) were found between RNA-seq and RT-qPCR results (Additional file 6), indicating that the measured changes in gene expression 
detected by RNA-seq reflected the actual transcriptome differences between the samples.

\section{Aphid population growth on resistant and susceptible sorghum 2- and 6-wk post-emergence}

Sorghum variety and growth stage had a significant effect on the mean daily change in $M$. sacchari densities (Fig. 8). The average change in aphid densities in susceptible sorghum was significantly greater than in resistant sorghum $\left(F_{1,32}=92.87 ; p\right.$-value $\left.<0.001\right)$, and aphid populations increased faster in the 6-wk old sorghum than in the 2 -wk old sorghum $\left(F_{1,32}=15.01 ; p\right.$-value $\left.<0.001\right)$. However, there was no interactive effect of these factors on the average change in aphid densities $\left(F_{1,32}=1.36\right.$; $p$-value $=0.253$ ). Aphid populations grew the slowest in the young resistant sorghum, and their numbers increased the most rapidly in the older susceptible sorghum. Rapid population growth of M. sacchari in susceptible sorghum in reproductive stages has been reported previously [32], and our outcomes corroborate those findings. Further, these results indicate that the robust transcriptional response to aphid herbivory in the younger resistant genotype is phenotypically reflected in the significantly diminished aphid performance on these plants.

\section{Conclusions}

The host plant resistance reported previously for the resistant genotype and manifested in significantly lower aphid densities in the greenhouse and field experiments [32] was reflected at the transcriptome level in our experiment. Specifically, transcriptome analysis of the susceptible and resistant sorghum genotypes revealed a suite of genes and pathways elicited in response to $M$. sacchari herbivory, particularly in the resistant and

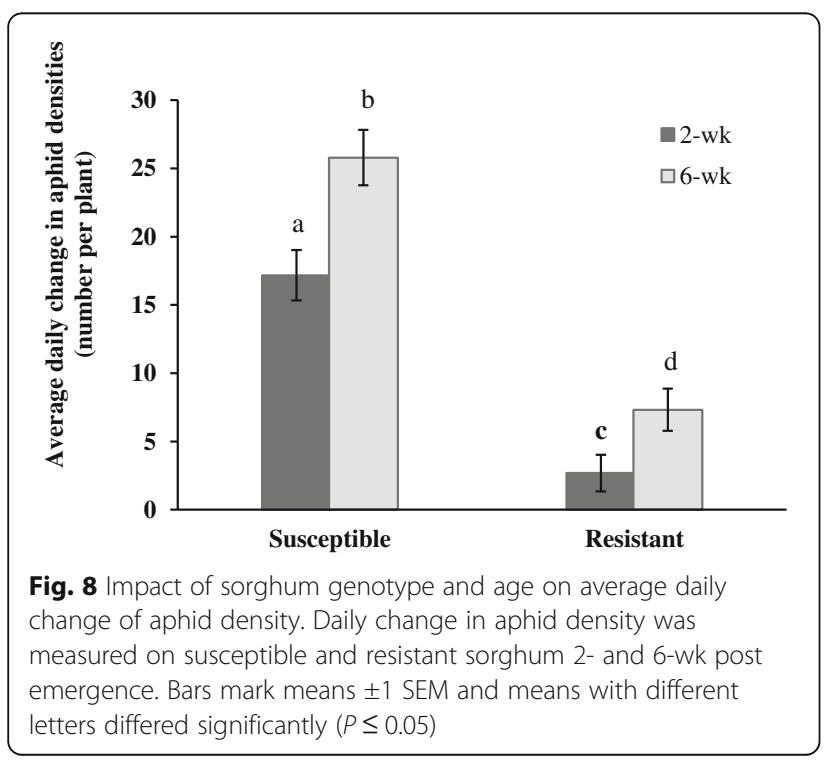

younger sorghum. These differentially expressed genes were involved in diverse processes including signaling, metabolism, and oxidative stress. We detected a higher number of DEGs and expression of a higher number of defense related genes in the resistant genotype in response to aphid herbivory than in the susceptible genotype. Further, the 2-wk old resistant genotype, in particular, mounted the most robust response to $M$. sachari feeding, and several genes and pathways provided insight into the mechanisms of aphid resistance.

The enriched GO terms and pathways highlighted the general differences between the two genotypes in response to aphid herbivory. The oxidation reduction GO term was highly enriched in the resistant genotype compared to the susceptible genotype. We also found that pathways coding for secondary metabolites, plant hormone signal transduction, plant-pathogen interaction, and glutathione metabolism were over-expressed in the resistant genotype. The resistant genotype also activated more genes involved in SA, JA, ET, and ABA signaling pathways. Our results suggested a potential cross-talk between SA and JA in the resistant genotype such that up-regulation of SA pathway genes negatively affected JA pathways genes through higher expression of JAZ genes that act as a negative regulator of JA biosynthesis pathway genes. Aphid herbivory also affected the balance between growth and defense related genes to the benefit of defense. Similar differences were noted when gene expression was compared between the 2-wk and 6-wk old sorghum - the number of DEGs, enriched GO terms, and significantly affected pathways were higher in the 2 -wk old plants than in the 6-wk old sorghum. On the other hand, the lower resistance of older plants may be related to the developmental stage of these plants. Sorghum at 6-wk after planting are usually at panicle initiation stage, and are especially sensitive to biotic and abiotic stress during this phase [127].

In conclusion, sugarcane aphid herbivory elicited the most robust transcriptional changes in the younger resistant genotype, and several pathways and specific genes provide insights into the mechanisms underlying host plant resistance to this invasive insect. Despite the apparent cross talk between SA and JA elicited by aphid herbivory, the younger resistant plants regulated their responses to abiotic stress, diverted resources to defense over growth, and induced strong responses to oxidative stress at the highest level compared to all other treatments. Lack of parallel responses in the older sorghum plants has relevant implications for aphid-sorghum interactions, and suggests lower host plant resistance in sorghum colonized at the onset of the reproductive stage. Further, unique induction of four WRKY genes only in the 2-wk resistant genotype highlights the likely importance of these TFs in the superior resistance of 
these plants to aphids, and should be considered in future studies. Further research should explore functional role of genes we found to be induced by $M$. sacchari to further clarify their impact on aphid-plant interactions.

\section{Methods}

\section{Sorghum growth and $M$. sacchari colony}

All experiments were conducted at the Texas A\&M AgriLife Research greenhouse complex located at the Plant Stress Laboratory in Bushland, TX. Two sorghum genotypes, aphid-susceptible (DKS 44-20, Dekalb *, Dekalb, IL), and aphid-resistant (DKS 37-07, Dekalb * Dekalb, IL) at 2- and 6-wk post-emergence grown under a long-day photoperiod regime were used in this study. The two genotypes were grown under controlled greenhouse conditions with a temperature range of $21 \pm 3{ }^{\circ} \mathrm{C}$ [62] to $30 \pm 3{ }^{\circ} \mathrm{C}$ [128]. Plants were grown in pots containing Redi-earth plug and seedling soil mix (Sun Grow Horticulture Inc., Agawam, MA) in $60 \times 60 \times 60 \mathrm{~cm}$ insect-proof rearing tents (MegaView Science Education Services Co., Taipei, Taiwan). Plants assigned to the 6-wk treatment were grown in $1 \times 1 \times 1 \mathrm{~m}$ cages constructed from PVC pipes and insect-proof mesh.

Sugarcane aphid colony originated from aphids collected from sorghum growing on a research farm affiliated with Texas A\&M AgriLife Research in Bushland, $\mathrm{TX}$, and no permits were required to enter the land or collect the aphids. The colony was maintained in the greenhouse for one year prior to the experiment. In order to confirm that the colony was genetically homogeneous, universal DNA primers were used to amplify a $710 \mathrm{bp}$ fragment of the mitochondrial cytochrome c oxidase subunit I gene (COI) following Vrijenhoek [129] methods. Two samples from two cages harboring the colony were collected for this analysis. The PCR products were purified using QIAGEN MinElute PCR purification kit (QIAGEN, Valencia, CA, USA) and sequenced on ABI 3130xl genetic analyzer by the Institute for Plant Genomics and Biotechnology at Texas A\&M University. The sequencing data from four samples were compared with each other using EMBOSS Needle [pairwise sequence alignment (Nucleotide)] (http://www.ebi.ac.uk/ Tools/psa/emboss_needle/nucleotide.html). There was no variation within and between a population that confirmed the integrity of the aphid colony. Further, the $\mathrm{COI}$ sequencing confirmed that the aphids were of different haplotype than previously described in sugarcane in the U.S. [27].

\section{Sample collection, RNA isolation, and sequencing}

The experiment was a $2 \times 2 \times 2$ factorial design with two levels of the sorghum genotype factor (susceptible, resistant), two levels of the sorghum age (2-wk, 6-wk), and two levels of aphid herbivory (present, absent). An individual pot was considered a biological replicate and three biological replications and three technical replications (i.e. individual plant in each pot) were included in this experiment. Half of the susceptible and half of the resistant plants were randomly assigned to one of the two sorghum age treatments and the herbivory treatment, which consisted of exposing two leaves in each plant to 15 aphids for $24 \mathrm{~h}$. The entire above-ground tissue of each 2-wk plant was collected for RNA-seq. Six-wk old plants were exposed to aphids in the same manner, with the exception of tissue collection for RNA extraction - only leaves exposed to the aphids and not entire plants were collected. Owing to the extensive size of the 6-wk old sorghum that surpassed $50 \mathrm{~cm}$ in height and had more than 10 fully unfurled leaves only the tissue that was directly exposed to aphid herbivory was collected and used in RNA extractions. Aphids on the 2 -wk old plants, on the other hand, were not confined to the single leaf to which they were introduced, and hence the entire plant (10-15 $\mathrm{cm}$ in height with three leaves) was collected. Samples were immediately frozen in liquid nitrogen $\left(\mathrm{LN}_{2}\right)$ and stored at $-80{ }^{\circ} \mathrm{C}$ until further sample processing.

Frozen leaf samples were ground under $\mathrm{LN}_{2}$ into a fine powder using a mortar and pestle. RNA was extracted from $100 \mathrm{mg}$ of frozen ground tissue using the miRNeasy Mini Kit (Qiagen, Valencia, CA, USA) and subsequently treated with DNase Max Kit (Qiagen, Valencia, CA, USA). RNA quality and quantity were assessed using the NanoVue Plus spectrophotometer (GE, Healthcare, Piscataway, NJ, USA). Three equimolar RNA samples extracted from three technical replicates for each biological replicate were pooled after extraction for RNA-seq template preparation. The quality of each pooled RNA sample was assessed with an Agilent 2100 Bioanalyzer (Agilent Technologies, Santa Clara, CA, USA) prior to RNA-seq template preparation by Texas AgriLife Research Genomic and Bioinformatics Services. Paired-end (PE) sequencing was performed on an Illumina HiSeq4000 using a 75 bp paired-end strategy on three biological replicates. RNA-seq template preparation and sequencing was completed at Texas AgriLife Research Genomics and Bioinformatics Center. The quality of RNA-seq reads was assessed using FastQC (http:// www.bioinformatics.babraham.ac.uk/projects/fastqc/).

\section{Gene expression analysis}

Sequence reads were imported into the CLC Genomics Workbench version 11 (Qiagen, Valencia, CA, USA) and mapped to the S. bicolor reference genome [Sbicolor_454 v3.1.1, www.phytozome.jgi.doe.gov, [130]. Based on the total read counts for each annotated gene, differential gene expression analyses were conducted using the Empirical Analysis of DGE tool, which implements the 'Exact Test' for two-group comparisons [131]. The 
transcriptional response of sorghum plants at 2- and 6-wk post-emergence and exposed to aphid herbivory was compared to aphid-free plants (the control) to identify DEGs. Differentially expressed genes were defined as having a fold change $\geq 1.9$ or $\leq-1.9$ with a false discovery rate (FDR) corrected $p$-value $<0.05$. For functional annotation, GO analysis was performed using AgriGO gene ontology analysis tools [132] to determine overrepresented GO categories in the up- and down-regulated DEGs, and significantly enriched GO terms were identified. Pathway analysis was performed using the KEGG database [133] to underline the pathways to which the up- and down-regulated DEGs contribute, and pathway enrichment analysis completed using the KOBAS server (version v.3) [134]. The overlaps between different sets of DEGs were generated with VENNY.2.1 (http://bioinfogp.cnb.csic.es/tools/venny/).

\section{RT-qPCR analysis of selected DEGs}

Five DEGs involved in plant-hormone signal transduction pathway were selected for validation of RNA-seq data using RT-qPCR. The same RNA samples from three biological replicates that were used for the sequencing were used for the validation of RNA-seq data. The total RNA was reverse-transcribed using Omniscript RT Kit (QIAGEN, Valencia, CA, USA). Primer pairs were designed using NCBI Primer-BLAST (http://www.ncbi.nlm. nih.gov/tools/primer-blast/), which are listed in Additional file 7. The RT-qPCR reaction was performed in a total volume of $20 \mu \mathrm{l}$, containing $1 \mu \mathrm{l}$ of diluted cDNA, $0.5 \mu \mathrm{l}$ of reverse and forward primers, $8 \mu \mathrm{l}$ of ddH2O, $10 \mu \mathrm{l}$ of SYBR Green Master Mix (Applied Biosystems, Foster City, CA, USA). Samples were run on a Applied Biosystems ViiA 7 Real-Time PCR system (Applied Biosystems, Foster City, CA, USA) according to the standard protocol as follows: $2 \mathrm{~min}$ at $50{ }^{\circ} \mathrm{C}, 10 \mathrm{~min}$ at $95{ }^{\circ} \mathrm{C}$, followed by 40 cycles of $15 \mathrm{~s}$ at $95^{\circ} \mathrm{C}$ for and $1 \mathrm{~min}$ at $60^{\circ}$ C. A melt curve was generated by the end of each PCR reaction to verify the formation of single peak and to exclude the possibility of primer dimer and non-specific product formation. All reactions were performed in duplicate, including the non-template control reactions. The relative quantitation of gene expression of RT-qPCR was measured via the $2^{-\Delta \Delta \mathrm{Ct}}$ method [135], with CYP (Cyclophilin/Peptidylprolyl Isomerase) gene as the endogenous reference gene that showed the highest stability among three tested reference genes. The correlation between the RNA-seq data and the RT-qPCR results was determined by Pearson's correlation coefficient.

\section{Aphid population growth evaluation}

In another set of experiments, differences in aphid densities on 2- and 6-wk susceptible and resistant sorghum genotypes was evaluated in early spring 2017.
Experiments were conducted in the greenhouse following the protocol described above (Sorghum growth and $M$. sacchari colony). The experimental design was a randomized complete design with two levels of sorghum growth stage (2- and 6-wk old sorghum), and two levels of the sorghum variety factor (Susceptible - DKS 44-20, and Resistant - DKS 37-07). The entire experiment was conducted twice (time block) and each of the treatment combinations was replicated a total of nine times across the two time blocks $(n=36)$. When sorghum reached the assigned growth stage, 15 sugarcane aphids were moved using a paintbrush and clippings of infested sorghum onto two leaves on each of the plants. The aphids were counted and replenished as needed $1 \mathrm{~h}$ following the introductions, and aphid densities following a $24 \mathrm{~h}$ acclimation period were used as the initial densities. Aphids were counted on entire plants every three days thereafter for $14 \mathrm{~d}$. The mean daily change in aphid densities per plant was the response variable recorded and analyzed.

\section{Statistical analyses for greenhouse evaluation}

The effects of sorghum age and variety on the average daily change in aphid densities was analyzed using two-way ANOVA with sorghum age and variety combination as a fixed factor and time block as a random factor. Owing to lack of a significant interaction between treatments and time block data from the two greenhouse experiments were combined. Effects of sorghum variety, age, and the interaction between the two factors were included in the analyses, and means separation tests were performed were appropriate with a Bonferroni adjustment. All analyses were performed in R [136].

\section{Additional files}

Additional file 1: Summary of RNA-seq reads from susceptible and resistant sorghum genotypes mapped to the sorghum genome (Sbicolor_454 version v.3.1.1). Unique RNA-seq reads mapping to exons, introns, and intergenic regions are shown as the percentage of total reads distributed to these annotated regions of the sorghum genome. (DOCX $23 \mathrm{~kb}$ )

Additional file 2: Differentially expressed genes (DEGs) in 2-wk resistant sorghum genotype in response to aphid herbivory. DEGs were defined as having a fold change $\geq 1.9$ or $\leq-1.9$ with a false discovery rate (FDR) adjusted $p$-value $<0.05$. (XLSX $431 \mathrm{~kb}$ )

Additional file 3: Differentially expressed genes (DEGs) in 2-wk susceptible sorghum genotype in response to aphid herbivory. DEGs were defined as having a fold change $\geq 1.9$ or $\leq-1.9$ with a false discovery rate (FDR) adjusted $p$-value $<0.05$. (XLSX $258 \mathrm{~kb}$ )

Additional file 4: Differentially expressed genes (DEGs) in 6-wk resistant sorghum genotype in response to aphid herbivory. DEGs were defined as having a fold change $\geq 1.9$ or $\leq-1.9$ with a false discovery rate (FDR) adjusted $p$-value $<0.05$. (XLSX $339 \mathrm{~kb})$

Additional file 5: Differentially expressed genes (DEGs) in 6-wk susceptible sorghum genotype in response to aphid herbivory. DEGs 
were defined as having a fold change $\geq 1.9$ or $\leq-1.9$ with a false discovery rate (FDR) adjusted $p$-value $<0.05$. (XLSX $106 \mathrm{~kb}$ )

Additional file 6: Real-time quantitative RT-PCR (RT-qPCR) validation of gene expression changes detected by RNA-seq. Data are shown as a fold change of the mean expression levels from three biological replicates. The correlation between the RNA-seg data and the RT-qPCR results is shown by Pearson's correlation coefficient $\left(R^{2}\right)$. (PDF $140 \mathrm{~kb}$ )

Additional file 7: Primers sequences used for RT-qPCR amplification of the five differentially expressed genes selected for validation. (DOCX $16 \mathrm{~kb})$

\section{Acknowledgements}

We would like to thank Eva Huff for assistance in the greenhouse, Li Paetzold for help in the laboratory, and Kristyne A. Varela for assistance in the sample preparation. We would also like to acknowledge three anonymous reviewers whose comments and suggestions greatly improved this manuscript.

\section{Funding}

This research was supported by funding from USDA NIFA (TEX09638), USDAARS, Areawide Pest Management of the Invasive Sugarcane Aphid in Grain Sorghum (3072-22000-016-00D), and Texas A\&M AgriLife Genomics and Bioinformatics Center. The funders had no role in the design of the study, collection, analysis, interpretation of the data, or in writing the manuscript.

\section{Availability of data and materials}

All raw sequencing reads have been submitted to the NCBI Sequence Read Archive and are available under BioProject ID: PRJNA451032 (http:// www.ncbi.nlm.nih.gov/bioproject/451032).

\section{Authors' contributions}

AS conceived the project, designed the experiments, and performed statistical analyses. MK conducted the experiments, performed the sample preparations for transcriptomics analysis including RNA extraction, RT-qPCR, and performed all bioinformatics data analyses. MK and AS wrote the manuscript. The final revision has been developed by both authors, and each author has given approval for the final version.

\section{Ethics approval and consent to participate}

Not applicable.

\section{Consent for publication}

Not applicable.

\section{Competing interests}

The authors declare that they have no competing interests.

\section{Publisher's Note}

Springer Nature remains neutral with regard to jurisdictional claims in published maps and institutional affiliations.

\section{Received: 20 April 2018 Accepted: 20 September 2018}

\section{Published online: 26 October 2018}

\section{References}

1. Walling LL. The myriad plant responses to herbivores. J Plant Growth Regul. 2000;19(2):195-216.

2. Howe GA, Jander G. Plant immunity to insect herbivores. Annu Rev Plant Biol. 2008:59:41-66.

3. Koch KG, Chapman K, Louis J, Heng-Moss T, Sarath G. Plant tolerance: a unique approach to control hemipteran pests. Front Plant Sci. 2016. doi:org/ https://doi.org/10.3389/fpls.2016.01363.

4. Wu J, Baldwin IT. New insights into plant responses to the attack from insect herbivores. Annu Rev Genet. 2010;44:1-24.

5. Foyer CH, Rasool B, Davey JW, Hancock RD. Cross-tolerance to biotic and abiotic stresses in plants: a focus on resistance to aphid infestation. J Exp Bot. 2016;67(7):2025-37.
6. Goggin FL, Zhu-Salzman K. Editorial overview: pests and resistance: social networking-studying the web of plant-insect interactions to improve host plant resistance. Curr Opin Insect Sci. 2015;9:v-viii.

7. Hawley CJ, Peairs FB, Randolph TL. Categories of resistance at different growth stages in halt, a winter wheat resistant to the Russian wheat aphid (Homoptera: Aphididae). J Econ Entomol. 2003;96(1):214-9.

8. Smith CM, Boyko EV. The molecular bases of plant resistance and defense responses to aphid feeding: current status. Entomol Exp Appl. 2007;122(1):1-16.

9. Hill CB, Li Y, Hartman GL. A single dominant gene for resistance to the soybean aphid in the soybean cultivar Dowling. Crop Sci. 2006;46(4):1601-5.

10. Omoigui L, Ekeuro G, Kamara A, Bello L, Timko M, Ogunwolu G. New sources of aphids [Aphis craccivora (Koch)] resistance in cowpea germplasm using phenotypic and molecular marker approaches. Euphytica. 2017;213(8):178-92.

11. Sharma HC, Bhagwat VR, Daware DG, Pawar DB, Munghate RS, Sharma SP, et al. Identification of sorghum genotypes with resistance to the sugarcane aphid Melanaphis sacchari under natural and artificial infestation. Plant Breed. 2014;133(1):36-44.

12. Reddy PS, Bhagwat VR, Prasad GS, Tonapi VA. Breeding for insect resistance in sorghum and millets. In: Arora $R$, Sandhu $S$, editors. Breeding insect resistant crops for sustainable agriculture. Singapore: Springer; 2017. p. 231-64

13. Bayoumy $\mathrm{MH}$, Perumal R, Michaud J. Comparative life histories of greenbugs and sugarcane aphids (Hemiptera: Aphididae) coinfesting susceptible and resistant sorghums. J Econ Entomol. 2015;109(1):385-91.

14. Reese JC, Schwenke JR, Lamont PS, Zehr DD. Importance and quantification of plant tolerance in crop pest management programs for aphids: greenbug resistance in sorghum. J Agric Entomol. 1994;11(3):255-70.

15. Johnson J, Rosenow D, Teetes G, Phillips J. Registration of 19 greenbug resistant sorghum germplasm lines1 (Reg. Nos. GP 79 to GP 97). Crop Sci. 1982;22(6):1272

16. Kofoid K, Harvey T. Registration of greenbug resistant sorghum germplasm lines KS 116 a/B through KS 120 a/B. Crop Sci. 2005:45(2):802-4.

17. Punnuri $S$, Huang $Y$. Identification and confirmation of greenbug resistance loci in an advanced mapping population of sorghum. J Agric Sci. 2017; 155(10):1610-22.

18. Huang Y. Improvement of crop protection against greenbug using the worldwide sorghum germplasm collection and genomics-based approaches. Plant Genet Resour. 2011:9(2):317-20.

19. Zapata SD, Villanueva R, Sekula D, Esparza-Diaz G, Duke K, Mutaleb M, editors. The economic impact of the sugarcane aphid on sorghum production. Southern Agricultural Economics Association Annual Meeting. San Antonio: Southern Agricultural Economics Association; 2016.

20. Villanueva R, Brewer M, Way M, Biles S, Sekula D, Bynum E, et al. Sugarcane aphid: a new pest of sorghum: Texas a\&M AgriLife extension: Ento-035; 2014.http://denton.agrilife.org/files/2013/08/ENTO-035-The-SugarcaneAphid-2014.pdf

21. Nibouche S, Costet L, Holt JR, Jacobson A, Pekarcik A, Sadeyen J, et al. Invasion of sorghum in the Americas by a new sugarcane aphid (Melanaphis sacchari) superclone. PLoS One. 2018;13(4):e0196124.

22. Bowling RD, Brewer MJ, Kerns DL, Gordy J, Seiter N, Elliott NE, et al. Sugarcane aphid (Hemiptera: Aphididae): a new pest on sorghum in North America. J Integr Pest Manag. 2016;7(1):1-13.

23. Brewer MJ, Gordy JW, Kerns DL, Woolley JB, Rooney WL, Bowling RD, Sugarcane aphid population growth, plant injury, and natural enemies on selected grain sorghum hybrids in Texas and Louisiana. J Econ Entomol. 2017;110(5):2109-18.

24. Tsutsui ND, Suarez AV, Holway DA, Case TJ. Reduced genetic variation and the success of an invasive species. Proc Natl Acad Sci. 2000;97(11):5948-53.

25. Bossdorf $\mathrm{O}$, Auge H, Lafuma L, Rogers WE, Siemann E, Prati D. Phenotypic and genetic differentiation between native and introduced plant populations. Oecologia. 2005;144(1):1-11.

26. Grapputo A, Boman S, Lindstroem L, Lyytinen A, Mappes J. The voyage of an invasive species across continents: genetic diversity of north American and European Colorado potato beetle populations. Mol Ecol. 2005;14(14): 4207-19.

27. Nibouche S, Fartek B, Mississipi S, Delatte H, Reynaud B, Costet L. Low genetic diversity in Melanaphis sacchari aphid populations at the worldwide scale. PLoS One. 2014;9(8):e106067.

28. Medina RF, Armstrong SJ, Harrison K. Genetic population structure of sugarcane aphid, Melanaphis sacchari, in sorghum, sugarcane, and Johnsongrass in the continental USA. Entomol Exp Appl. 2017;162(3):358-65. 
29. Harris-Shultz K, Ni X, Wadl PA, Wang X, Wang H, Huang F, et al. Microsatellite markers reveal a predominant sugarcane aphid (Homoptera: Aphididae) clone is found on sorghum in seven states and one territory of the USA. Crop Sci. 2017;57(4):2064-72.

30. Smith CM. Plant resistance in arthropod pest management systems. In: Smith CM, editor. Plant resistance to arthropods: molecular and conventional approaches. The Netherlands: Springer Science \& Business Media; 2005. p. 381-412.

31. Smith CM, Chuang WP. Plant resistance to aphid feeding: behavioral, physiological, genetic and molecular cues regulate aphid host selection and feeding. Pest Manag Sci. 2014;70(4):528-40.

32. Szczepaniec A. Interactive effects of crop variety, insecticide seed treatment, and planting date on population dynamics of sugarcane aphid (Melanaphis sacchari) and their predators in late-colonized sorghum. Crop Prot. 2018;109:72-9.

33. Mbulwe L, Peterson GC, Scott-Armstrong J, Rooney WL. Registration of sorghum germplasm Tx3408 and T×3409 with tolerance to sugarcane aphid [Melanaphis sacchari (Zehntner)]. J Plant Regist. 2016;10(1):51-6.

34. Züst T, Agrawal AA. Mechanisms and evolution of plant resistance to aphids. Nat Plants. 2016. https://doi.org/10.1038/NPLANTS.2015.206.

35. Dogimont C, Bendahmane A, Chovelon V, Boissot N. Host plant resistance to aphids in cultivated crops: genetic and molecular bases, and interactions with aphid populations. C R Biol. 2010;333(6-7):566-73.

36. Boissot N, Thomas S, Sauvion N, Marchal C, Pavis C, Dogimont C. Mapping and validation of QTLs for resistance to aphids and whiteflies in melon. Theor Appl Genet. 2010;121(1):9-20.

37. Lee S, Cassone BJ, Wijeratne A, Jun T-H, Michel AP, Mian MR. Transcriptomic dynamics in soybean near-isogenic lines differing in alleles for an aphid resistance gene, following infestation by soybean aphid biotype 2. BMC Genomics. 2017;18(1):472-83.

38. Liang D, Liu M, Hu Q, He M, Qi X, Xu Q, et al. Identification of differentially expressed genes related to aphid resistance in cucumber (Cucumis sativus L. ). Sci Rep. 2015. https://doi.org/10.1038/srep09645.

39. Prochaska TJ, Donze-Reiner T, Marchi-Werle L, Palmer N, Hunt TE, Sarath G, et al. Transcriptional responses of tolerant and susceptible soybeans to soybean aphid (Aphis glycines Matsumura) herbivory. Arthropod Plant Interact. 2015;9(4):347-59.

40. Pieterse CM, Van der Does D, Zamioudis C, Leon-Reyes A, Van Wees SC. Hormonal modulation of plant immunity. Annu Rev Cell Dev Biol. 2012;28(1):489-521.

41. Erb M, Meldau S, Howe GA. Role of phytohormones in insect-specific plant reactions. Trends Plant Sci. 2012;17(5):250-9.

42. Bari R, Jones JD. Role of plant hormones in plant defence responses. Plant Mol Biol. 2009;69(4):473-88.

43. Bennett RN, Wallsgrove RM. Secondary metabolites in plant defence mechanisms. New Phytol. 1994;127(4):617-33.

44. Kessler A, Baldwin IT. Plant responses to insect herbivory: the emerging molecular analysis. Annu Rev Plant Biol. 2002;53(1):299-328.

45. Toan TN, Thanh Huyen TTV, Chung MV. Antioxidative defense response to aphid-induced oxidative stress in Glycine max (L.) Merr. cv. "Nam Dan”. Vietnam J Sci Tech. 2016;54(6):719-28.

46. Li J, Zhu L, Hull JJ, Liang S, Daniell H, Jin S, et al. Transcriptome analysis reveals a comprehensive insect resistance response mechanism in cotton to infestation by the phloem feeding insect Bemisia tabaci (whitefly). Plant Biotechnol J. 2016;14(10):1956-75.

47. Gutsche A, Heng-Moss T, Sarath G, Twigg P, Xia Y, Lu G, et al. Gene expression profiling of tolerant barley in response to Diuraphis noxia (Hemiptera: Aphididae) feeding. Bull Entomol Res. 2009;99(2):163-73.

48. Donze-Reiner T, Palmer NA, Scully ED, Prochaska TJ, Koch KG, Heng-Moss T, et al. Transcriptional analysis of defense mechanisms in upland tetraploid switchgrass to greenbugs. BMC Plant Biol. 2017;17(1):46-66.

49. Bansal R, Mian M, Mittapalli O, Michel AP. RNA-Seq reveals a xenobiotic stress response in the soybean aphid, Aphis glycines, when fed aphidresistant soybean. BMC Genomics. 2014;15(1):972-85.

50. Bidart-Bouzat MG, Imeh-Nathaniel A. Global change effects on plant chemical defenses against insect herbivores. J Integr Plant Biol. 2008;50(11):1339-54.

51. Patra B, Schluttenhofer C, Wu Y, Pattanaik S, Yuan L. Transcriptional regulation of secondary metabolite biosynthesis in plants. Biochim Biophys Acta. 2013;1829(11):1236-47.

52. Vannozzi A, Dry IB, Fasoli M, Zenoni S, Lucchin M. Genome-wide analysis of the grapevine stilbene synthase multigenic family: genomic organization and expression profiles upon biotic and abiotic stresses. BMC Plant Biol. 2012;12(1):130-51.
53. Tu X, Liu Z, Zhang Z. Comparative transcriptomic analysis of resistant and susceptible alfalfa cultivars (Medicago sativa L.) after thrips infestation. BMC Genomics. 2018. https://doi.org/10.1186/s12864-018-4495-2.

54. Ponzio C, Papazian S, Albrectsen BR, Dicke M, Gols R. Dual herbivore attack and herbivore density affect metabolic profiles of Brassica nigra leaves. Plant Cell Environ. 2017;40(8):1356-67.

55. Wink M. Plant breeding: importance of plant secondary metabolites for protection against pathogens and herbivores. Theor Appl Genet. 1988;75(2):225-33.

56. Dubey NK, Goel R, Ranjan A, Idris A, Singh SK, Bag SK, et al. Comparative transcriptome analysis of Gossypium hirsutum L. in response to sap sucking insects: aphid and whitefly. BMC Genomics. 2013;14(1):241-60.

57. Scholz S, Heyer M, Vadassery J, Mithöfer A. A role for calmodulin-like proteins in herbivore defense path-ways in plants. Endocytobiosis Cell Res. 2016;27(1):1-12.

58. Coppola V, Coppola M, Rocco M, Digilio MC, D'Ambrosio C, Renzone G, et al. Transcriptomic and proteomic analysis of a compatible tomato-aphid interaction reveals a predominant salicylic acid-dependent plant response. BMC Genomics. 2013;14(1):515-32.

59. Yu H, Luscombe NM, Qian J, Gerstein M. Genomic analysis of gene expression relationships in transcriptional regulatory networks. Trends Genet. 2003;19(8):422-7.

60. Ranty B, Aldon D, Cotelle V, Galaud J-P, Thuleau P, Mazars C. Calcium sensors as key hubs in plant responses to biotic and abiotic stresses. Front Plant Sci. 2016. doi:org/https://doi.org/10.3389/fpls.2016.00327.

61. Tena G, Boudsocq M, Sheen J. Protein kinase signaling networks in plant innate immunity. Curr Opin Plant Biol. 2011;14(5):519-29.

62. Rentel MC, Lecourieux D, Ouaked F, Usher SL, Petersen L, Okamoto H, et al. OXI1 kinase is necessary for oxidative burst-mediated signalling in Arabidopsis. Nature. 2004;427(6977):858-561.

63. Fuchs S, Grill E, Meskiene I, Schweighofer A. Type 2 C protein phosphatases in plants. FEBS J. 2013;280(2):681-93.

64. Moorhead GB, Trinkle-Mulcahy L, Ulke-Lemée A. Emerging roles of nuclear protein phosphatases. Nat Rev Mol Cell Biol. 2007;8(3):234-44.

65. Schweiger R, Heise AM, Persicke M, Müller C. Interactions between the jasmonic and salicylic acid pathway modulate the plant metabolome and affect herbivores of different feeding types. Plant Cell Environ. 2014;37(7):1574-85.

66. Vos I, Pieterse C, Wees S. Costs and benefits of hormone-regulated plant defences. Plant Pathol. 2013;62(S1):43-55.

67. Li Q, Xie Q-G, Smith-Becker J, Navarre DA, Kaloshian I. Mi-1-mediated aphid resistance involves salicylic acid and mitogen-activated protein kinase signaling cascades. Mol Plant-Microbe Interact. 2006;19(6):655-64.

68. Maffei ME, Mithöfer A, Boland W. Before gene expression: early events in plant-insect interaction. Trends Plant Sci. 2007;12(7):310-6.

69. Wu Y, Zhang D, Chu JY, Boyle P, Wang Y, Brindle ID, et al. The Arabidopsis NPR1 protein is a receptor for the plant defense hormone salicylic acid. Cell Rep. 2012;1(6):639-47.

70. Medina-Puche L, Castelló MJ, Canet JV, Lamilla J, Colombo ML, Tornero P. $\beta$ Carbonic anhydrases play a role in salicylic acid perception in Arabidopsis. PLoS One. 2017;12(7):e0181820.

71. Dar TA, Uddin M, Khan MMA, Hakeem K, Jaleel H. Jasmonates counter plant stress: a review. Environ Exp Bot. 2015;115:49-57.

72. Koo AJ. Metabolism of the plant hormone jasmonate: a sentinel for tissue damage and master regulator of stress response. Phytochem Rev. 2017;17(1):1-30.

73. Lortzing T, Steppuhn A. Jasmonate signalling in plants shapes plant-insect interaction ecology. Curr Opin Insect Sci. 2016;14:32-9.

74. Kazan K, Manners JM. MYC2: the master in action. Mol Plant. 2013;6(3):686-703.

75. Dombrecht B, Xue GP, Sprague SJ, Kirkegaard JA, Ross JJ, Reid JB, et al. MYC2 differentially modulates diverse jasmonate-dependent functions in Arabidopsis. Plant Cell. 2007;19(7):2225-45.

76. Wei J, van Loon JJ, Gols R, Menzel TR, Li N, Kang L, et al. Reciprocal crosstalk between jasmonate and salicylate defence-signalling pathways modulates plant volatile emission and herbivore host-selection behaviour. J Exp Bot. 2014;65(12):3289-98

77. Thaler JS, Humphrey PT, Whiteman NK. Evolution of jasmonate and salicylate signal crosstalk. Trends Plant Sci. 2012;17(5):260-70.

78. Caarls L, Pieterse CM, Van Wees S. How salicylic acid takes transcriptional control over jasmonic acid signaling. Front Plant Sci. 2015. doi:org/https:// doi.org/10.3389/fpls.2015.00170.

79. Szczepaniec A, Raupp MJ, Parker RD, Kerns D, Eubanks MD. Neonicotinoid insecticides alter induced defenses and increase susceptibility to spider mites in distantly related crop plants. PLoS One. 2013;8(5):e62620. 
80. De Vos M, Van Oosten VR, Van Poecke RM, Van Pelt JA, Pozo MJ, Mueller MJ, et al. Signal signature and transcriptome changes of Arabidopsis during pathogen and insect attack. Mol Plant-Microbe Interact. 2005;18(9):923-37.

81. Walling LL. Avoiding effective defenses: strategies employed by phloemfeeding insects. Plant Physiol. 2008;146(3):859-66.

82. Zhang P, Zhu X, Huang F, Liu Y, Zhang J, Lu Y, et al. Suppression of jasmonic acid-dependent defense in cotton plant by the mealybug Phenacoccus solenopsis. PLoS One. 2011;6(7):e22378.

83. Zarate SI, Kempema LA, Walling LL. Silverleaf whitefly induces salicylic acid defenses and suppresses effectual jasmonic acid defenses. Plant Physiol. 2007;143(2):866-75.

84. Moran PJ, Thompson GA. Molecular responses to aphid feeding in Arabidopsis in relation to plant defense pathways. Plant Physiol. 2001;125(2):1074-85.

85. Tuteja N. Abscisic acid and abiotic stress signaling. Plant Signal Behav. 2007; 2(3):135-8.

86. Danquah A, de Zelicourt A, Colcombet J, Hirt H. The role of ABA and MAPK signaling pathways in plant abiotic stress responses. Biotechnol Adv. 2014; 32(1):40-52

87. Dinh ST, Baldwin IT, Galis I. The HERBIVORE ELICITOR-REGULATED1 (HER1) gene enhances abscisic acid levels and defenses against herbivores in Nicotiana attenuata plants. Plant Physiol. 2013. doi:org/https:/doi.org/10.1104/pp.113.221150.

88. Vos IA, Verhage A, Schuurink RC, Watt LG, Pieterse CM, Van Wees S. Onset of herbivore-induced resistance in systemic tissue primed for jasmonatedependent defenses is activated by abscisic acid. Front Plant Sci. 2013. doi: org/https://doi.org/10.3389/fpls.2013.00539.

89. Bodenhausen N, Reymond P. Signaling pathways controlling induced resistance to insect herbivores in Arabidopsis. Mol Plant-Microbe Interact. 2007;20(11):1406-20.

90. Zong W, Tang N, Yang J, Peng L, Ma S, Xu Y, et al. Feedback regulation of ABA signaling and biosynthesis by a bZIP transcription factor targets drought resistance related genes. Plant Physiol. 2016. https:/doi.org/10.1104/pp.16.00469.

91. Hillwig MS, Chiozza M, Casteel CL, Lau ST, Hohenstein J, Hernández E, et al. Abscisic acid deficiency increases defence responses against Myzus persicae in Arabidopsis. Mol Plant Pathol. 2016;17(2):225-35.

92. Zhu-Salzman K, Salzman RA, Ahn J-E, Koiwa H. Transcriptional regulation of sorghum defense determinants against a phloem-feeding aphid. Plant Physiol. 2004;134(1):420-31.

93. Yue J, Hu X, Huang J. Origin of plant auxin biosynthesis. Trends Plant Sci. 2014;19(12):764-70.

94. Berens ML, Berry HM, Mine A, Argueso CT, Tsuda K. Evolution of hormone signaling networks in plant defense. Annu Rev Phytopathol. 2017;55:401-25.

95. Attaran E, Major IT, Cruz JA, Rosa BA, Koo AJ, Chen J, et al. Temporal dynamics of growth and photosynthesis suppression in response to jasmonate signaling. Plant Physiol. 2014;165(3):1302-14.

96. Huot B, Yao J, Montgomery BL, He SY. Growth-defense tradeoffs in plants: a balancing act to optimize fitness. Mol Plant. 2014;7(8):1267-87.

97. Ding X, Cao Y, Huang L, Zhao J, Xu C, Li X, et al. Activation of the indole-3acetic acid-amido synthetase $\mathrm{GH} 3-8$ suppresses expansin expression and promotes salicylate-and jasmonate-independent basal immunity in rice. Plant Cell. 2008;20(1):228-40.

98. Naseem M, Kaltdorf M, Dandekar T. The nexus between growth and defence signalling: auxin and cytokinin modulate plant immune response pathways. J Exp Bot. 2015;66(16):4885-96.

99. Grones P, Friml J. Auxin transporters and binding proteins at a glance. J Cell Sci. 2015;128:1-7.

100. Park J-E, Park J-Y, Kim Y-S, Staswick PE, Jeon J, Yun J, et al. GH3-mediated auxin homeostasis links growth regulation with stress adaptation response in Arabidopsis. J Biol Chem. 2007;282(13):10036-46.

101. Kazan K, Manners JM. Linking development to defense: auxin in plantpathogen interactions. Trends Plant Sci. 2009;14(7):373-82.

102. Giron D, Frago E, Glevarec G, Pieterse CM, Dicke M. Cytokinins as key regulators in plant-microbe-insect interactions: connecting plant growth and defence. Funct Ecol. 2013;27(3):599-609.

103. Broekgaarden C, Voorrips RE, Dicke M, Vosman B. Transcriptional responses of Brassica nigra to feeding by specialist insects of different feeding guilds. Insect Sci. 2011;18(3):259-72.

104. Dubois M, Van den Broeck L, Inzé D. The pivotal role of ethylene in plant growth. Trends Plant Sci. 2018;23(4):311-23.

105. Diezel C, Allmann S, Baldwin IT. Mechanisms of optimal defense patterns in Nicotiana attenuata: flowering attenuates herbivory-elicited ethylene and jasmonate signaling. J Integr Plant Biol. 2011;53(12):971-83.
106. Lu J, Li J, Ju H, Liu X, Erb M, Wang X, et al. Contrasting effects of ethylene biosynthesis on induced plant resistance against a chewing and a piercingsucking herbivore in rice. Mol Plant. 2014;7(11):1670-82.

107. Louis J, Basu S, Varsani S, Castano-Duque L, Jiang V, Williams WP, et al. Ethylene contributes to maize insect resistance1-mediated maize defense against the phloem sap-sucking corn leaf aphid. Plant Physiol. 2015;169(1):313-24.

108. Lv M, Kong H, Liu H, Lu Y, Zhang C, Liu J, et al. Induction of phenylalanine ammonia-lyase (PAL) in insect damaged and neighboring undamaged cotton and maize seedlings. Int J Pest Manag. 2017;63(2):166-71.

109. Chaman ME, Copaja SV, Argandoña VH. Relationships between salicylic acid content, phenylalanine ammonia-lyase (PAL) activity, and resistance of barley to aphid infestation. J Agric Food Chem. 2003;51(8):2227-31.

110. Sytykiewicz H, Chrzanowski G, Czerniewicz P, Sprawka I, Łukasik I, Goławska S, et al. Expression profiling of selected glutathione transferase genes in Zea mays (L.) seedlings infested with cereal aphids. PLoS One. 2014;9(11):e111863

111. Hernández J, Barba-Espín G, Diaz-Vivancos P. Glutathione-Mediated Biotic Stress Tolerance in Plants. Glutathione in Plant Growth, Development, and Stress Tolerance. Switzerland: Springer; 2017. p. 309-29.

112. Zechmann B. Compartment-specific importance of glutathione during abiotic and biotic stress. Front Plant Sci. 2014. doi:org/https://doi.org/10.3389/fpls.2014.00566.

113. Kawano T. Roles of the reactive oxygen species-generating peroxidase reactions in plant defense and growth induction. Plant Cell Rep. 2003;21(9):829-37.

114. Gulsen O, Eickhoff T, Heng-Moss T, Shearman R, Baxendale F, Sarath G, et al. Characterization of peroxidase changes in resistant and susceptible warmseason turfgrasses challenged by Blissus occiduus. Arthropod Plant Interact. 2010;4(1):45-55

115. Mai VC, Bednarski W, Borowiak-Sobkowiak B, Wilkaniec B, Samardakiewicz S, Morkunas I. Oxidative stress in pea seedling leaves in response to Acyrthosiphon pisum infestation. Phytochemistry. 2013;93:49-62.

116. Jun $X, X-y$ WANG, W-z GUO. The cytochrome P450 superfamily: key players in plant development and defense. J Integr Agric. 2015;14(9):1673-86.

117. Rushton PJ, Somssich IE, Ringler P, Shen QJ. WRKY transcription factors. Trends Plant Sci. 2010;15(5):247-58.

118. Satapathy L, Kumar D, Mukhopadhyay KWRKY. Transcription factors: involvement in plant-pathogen interactions. In: Shukla P, editor. Recent advances in applied microbiology: Springer; 2017. p. 229-46.

119. Banerjee A, Roychoudhury A. WRKY proteins: signaling and regulation of expression during abiotic stress responses. Singapore: Sci World J. 2015. doi: org/https://doi.org/10.1155/2015/807560.

120. Kuśnierczyk A, Winge P, Jørstad TS, Troczyńska J, Rossiter JT, Bones AM. Towards global understanding of plant defence against aphids-timing and dynamics of early Arabidopsis defence responses to cabbage aphid (Brevicoryne brassicae) attack. Plant Cell Environ. 2008;31(8):1097-115.

121. Li J, Brader G, Kariola T, Tapio Palva E. WRKY70 modulates the selection of signaling pathways in plant defense. Plant J. 2006;46(3):477-91.

122. Higashi K, Ishiga Y, Inagaki Y, Toyoda K, Shiraishi T, Ichinose Y. Modulation of defense signal transduction by flagellin-induced WRKY41 transcription factor in Arabidopsis thaliana. Mol Genet Genomics. 2008;279(3):303-12.

123. Huang P-Y, Catinot J, Zimmerli L. Ethylene response factors in Arabidopsis immunity. J Exp Bot. 2016;67(5):1231-41.

124. Tsuda K, Somssich IE. Transcriptional networks in plant immunity. New Phytol. 2015;206(3):932-47.

125. Alves MS, Dadalto SP, Gonçalves AB, De Souza GB, Barros VA, Fietto LG. Plant bZIP transcription factors responsive to pathogens: a review. Int J Mol Sci. 2013;14(4):7815-28.

126. Nuruzzaman M, Sharoni AM, Kikuchi S. Roles of NAC transcription factors in the regulation of biotic and abiotic stress responses in plants. Front Microbiol. 2013. doi:org/https://doi.org/10.3389/fmicb.2013.00248.

127. Kelly J. Chapter 1-growth and development. In: Espinoza L, Kelly J, editors. Grain Sorghum production handbook. Cooperative Extention service: University of Arkansas. Fayetteville, AR. 2004. https://www.uaex.edu/ publications/pdf/mp297/MP297.pdf.

128. Chisholm ST, Coaker G, Day B, Staskawicz BJ. Host-microbe interactions: shaping the evolution of the plant immune response. Cell. 2006;124(4):803-14.

129. Vrijenhoek R. DNA primers for amplification of mitochondrial cytochrome $c$ oxidase subunit I from diverse metazoan invertebrates. Mol Mar Biol Biotechnol. 1994;3(5):294-9.

130. Paterson AH, Bowers JE, Bruggmann R, Dubchak I, Grimwood J, Gundlach H, et al. The Sorghum bicolor genome and the diversification of grasses. Nature. 2009;457(7229):551-6. 
131. Robinson MD, McCarthy DJ, Smyth GK. edgeR: a bioconductor package for differential expression analysis of digital gene expression data. Bioinformatics. 2010;26(1):139-40.

132. Du Z, Zhou X, Ling Y, Zhang Z, Su Z. agriGO: a GO analysis toolkit for the agricultural community. Nucleic Acids Res. 2010;38:W64-70.

133. Kanehisa M, Goto S. KEGG: Kyoto encyclopedia of genes and genomes. Nucleic Acids Res. 2000;28(1):27-30.

134. Xie C, Mao X, Huang J, Ding Y, Wu J, Dong S, et al. KOBAS 2.0: a web server for annotation and identification of enriched pathways and diseases. Nucleic Acids Res. 2011;39(2):W316-W22.

135. Livak KJ, Schmittgen TD. Analysis of relative gene expression data using real-time quantitative PCR and the $2^{-\Delta \Delta \top}$ method. Methods. 2001;25(4):402-8.

136. Team RC. R: a language and environment for statistical computing. Vienna: R Foundation for statistical computing. 2012. ISBN 3-900051-07-02012

Ready to submit your research? Choose BMC and benefit from:

- fast, convenient online submission

- thorough peer review by experienced researchers in your field

- rapid publication on acceptance

- support for research data, including large and complex data types

- gold Open Access which fosters wider collaboration and increased citations

- maximum visibility for your research: over $100 \mathrm{M}$ website views per year

At BMC, research is always in progress.

Learn more biomedcentral.com/submissions 